\title{
Uber hydrolytische Spaltungen von Proteinen durch Einwirkung von Pepsin, Trypsin, Säuren und Alkalien.

\author{
Von
}

V. Henriques und J. K. Gjaldbæk.

(Aus dem physiologischen Laboratorium der kgl. tierärztlichen und landwirtschaftlichen Hochschule, Kopenhagen.)

(Der Redaktion zugegangen am 4. Oktober 1911.)

Durch die von S.P. L. Sören sen ausgearbeitete Methode, ${ }^{1}$ ) mittels welcher man den Abbau von Proteinen Schritt um Schritt zu verfolgen vermag, ist uns die Möglichkeit eröffnet worden, uns neue Aufschlüsse über die proteolytischen Vorgänge bei Einwirkung von Fermenten oder bei Beeinflussung von Säuren oder Alkalien zu verschaffen. Namentlich hat eine Anwendung von Sörensens Formoltitrierung in der Weise, daß die Titrierung nicht auf einmal geschieht, sondern in Stadien ${ }^{2}$ ) ausgeführt wird, wie aus den unten angeführten Versuchen hervorgehen wird, ergeben, daß man in den Stand gesetzt wird, zwischen der Wirkungsweise der verschiedenen Fermente zu unterscheiden.

Bevor wir unsere Versuche eingehender besprechen, werden wir ganz kurz das von uns benutzte Verfahren angeben.

Es wird erst eine Lösung des Proteins, dessen Spaltung untersucht werden soll, hergestellt, und außerdem eine Lösung des Ferments. Nach Vermischung und Erwärmung auf $37^{\circ}$ werden drei Proben entnommen; die eine wird zurTotalstickstoffbestimmung benutzt, die zweite zur Ammoniakbestimmung und schließlich die dritte (nach Neutralisation mit empfindlichem Lackmuspapier) zur Formoltitrierung in Stadien.

1) S. P. L. Sörensen, Biochem. Zeitschrift, Bd. 7 (1907).

$\left.{ }^{2}\right)$ V. Henriques und S. P. L. Sörensen, Diese Zeitschrift, Bd. 63 (1909). 
Alle Stickstoffbestimmungen sind nach Kjeldahl' ${ }^{1}$ ) ausgeführt. Betreffs des Ammoniaks verweisen wir auf eine unserer früheren Arbeiten. ${ }^{2}$ )

Die Formoltitrierung in Stadien ist in folgender Weise ausgeführt: Nachdem $25 \mathrm{ccm}$ der Flüssigkeit gegen Lackmuspapier neutralisiert worden sind, wird Phenolphthalein zugesetzt und danach $\mathrm{n} / 5-\mathrm{NaOH}$ bis zu schwach roter Farbe (1. Stadium); darauf wird wieder $\mathrm{n} / \overline{5}-\mathrm{NaOH}$ zugesetzt bis zu stark roter Farbe, d. h. gleich der Farbe der Kontrollösung (2. Stadium); nun wird neutrale Formollösung zugesetzt und die rote Farbe verschwindet; es wird wieder $\mathrm{n} /{ }_{5}-\mathrm{NaOH}$ zugesetzt bis zu schwach roter Farbe (3. Stadium), und danach wird weiter titriert, bis die stark rote Farbe der Kontrolle erreicht ist (4. Stadium).

Bei Titrierung in vollkommen klaren Lösungen verursachte der Umschlag gewöhnlich keine Schwierigkeit; dagegen war der Umschlag bei Titrierung in Flüssigkeiten mit schwächeren oder stärkeren Ausfällungen weniger gut, namentlich wo es sich um die Feststellung des Augenblicks handelte, wo zu Ende des 1. Stadiums die schwach rote Farbe erscheint.

Es wurden folgende Proteine angewendet: Gedörrtes Hühnereiweiß (gewöhnliche Handelsware), Ciasein (Hammarsten), Witte-Pepton, Edestin (Höchst), Gliadin (aus Weizenmehl hergestellt), Gelatine (gewöhnliche Handelsware) und gewöhnliches mageres Rindfleisch.

Die Versuche wurden angestellt mit Lösungen (oder Aufschwemmungen) in bezw. sauren oder schwach alkalischen Flüssigkeiten von ca. $2 \%$.

Die hier angewendeten Fermente sind Pepsin (Parke, Davis \& Co.), Trypsin (Pankreatin, Rhenania). Die Menge des zugesetzten Ferments schwankte etwas in den verschiedenen Versuchen; übrigens ist die angewendete Menge bei jedem einzelnen Versuch in den Tabellen angegeben.

Außer über die Wirkung der beiden genannten Fermente je für sich haben wir Versuche angestellt über die Wirkung des Pepsins auf trypsingespaltete Proteine und über die Wirkung

1) R. Ko efoed, Diese Zeitschrift, Bd. 69.

2) V. Henriques und J. K. Gjaldbæk, Diese Zeitschrift, Bd. 67. 
des Trypsins auf pepsingespaltete Proteine. Bei den Versuchen über die Säure- und Alkaliwirkungen auf die Proteine bestand das Verfahren einfach darin, daß wir die Proteine bei verschiedenen Temperaturen (zwischen $37^{\circ}$ und $150^{\circ}$ variierend) kürzere oder längere Zeit mit Schwefelsäure, Salzsäure oder Natronlauge verschiedener Stärke stehen ließen.

Schließlich sei erwähnt, daß wir soweit möglich die Wasserstoffionenkonzentration (mittels S. P. L. Sörensens kolorimetrischer Methode ${ }^{1}$ )) so einstellten, daß die Pepsinverdauung bei einer Wasserstoffionenkonzentration von $10 \div 1,5$, die Trypsinverdauung bei einer solchen von $10 \div 7,1-10 \div 8,0$ stattfand.

Zur Erläuterung der Tabellen sei folgendes angeführt:

Die erste Kolonne, bezeichnet $\mathrm{P}_{\mathrm{H}}$, gibt die Wasserstoffionenkonzentration an, wo diese bestimmt worden ist. Die folgenden Kolonnen: 1, 2, 3, 4 und $\mathrm{K}$ geben die 4 Stadien der Titrierung und die Stärke der Kontrollösung an, ausgedrückt in $\mathrm{n} / 5-\mathrm{NaOH}$ und bezogen auf $100 \mathrm{mg}$ Stickstoff. Die Titrierung geschah, wie oben erwähnt, in $25 \mathrm{ccm}$ Flüssigkeit, die gewöhnlich um $70 \mathrm{mg} \mathrm{N}$ enthielt. Die folgende Kolonne, bezeichnet: Formoltitrierbarer $\mathrm{N}$ in Prozenten des Total- $\mathrm{N}$, gibt an, wieviele Prozent des Totalstickstoffes sich formoltitrieren lassen. Die Zahlen sind in der Weise gewonnen, daß von der Zahl der Kolonne 4 die Zahl der Kontrolle (Kolonne K) subtrahiert worden ist; die dadurch gewonnene Zahl wird nun, mit 2,8 multipliziert, einfach die Menge von formoltitrierbarem $\mathrm{N}$ in Prozenten des Total-N angeben. Die Formoltitrierung geschah überall ohne Entfernung von Ammoniak, woraus folgt, daß der sogenannte formoltitrierbare Stickstoff als Aminogruppe + Ammoniak vorhanden ist. Wir müssen hier darauf aufmerksam machen, daß man, wie zuerst von L. de Jager angegeben, ${ }^{2}$ ) unter gewissen Verhältnissen weniger formoltitrierbaren Stickstoff vorfinden kann, als wenn man Ammoniak und die Aminogruppen je für sich bestimmt. V. Henriques und

1) S. P. L. Sörensen, Biochem. Zeitschrift, Bd. 22.

$\left.{ }^{2}\right)$ L. de Jager, Diese Zeitschrift, Bd. 63. 
S. P. L. Sörensen haben dies Verhältnis näher untersucht und gezeigt, $\left.{ }^{1}\right)$ daß der Fehler nur von nennenswerter Bedeutung ist, wenn die Ammoniakmenge sehr groß ist. Bei den sehr geringen Ammoniakmengen unserer Verdauungsflüssigkeiten spielt dieses Verhältnis somit keine Rolle, wovon wir uns übrigens durch Formoltitrierung der Flüssigkeiten mit Ammoniak und durch Vergleichung der gefundenen Zahl mit derjenigen überzeugt haben, die man erhält, wenn man das Ammoniak durch $\mathrm{Ab}$ destillation im Vakuum bestimmt und danach im übriggebliebenen Rest formoltitriert; wir fanden hier eine so gute Übereinstimmung, wie sich nur erwarten ließ.

Die Kolonne Ammoniak- $\mathrm{N}$ in Prozent des Totalstickstoffs bedarf keiner weiteren Erklärung.

Die letzte Kolonne $1-(4 \div \mathrm{K})$ gibt das Verhältnis an zwischen der dem ersten Stadium der Titrierung entsprechenden Zahl und derjenigen, die das letzte und vierte Stadium $\div$ der Zahl der Kontrollösung angibt. Es zeigt sich, daß dieses Verhältnis von großer Bedeutung ist, indem es sich teils ändert, allmählich wie die Fermentwirkung fortschreitet, und sich teils als wesentlich verschieden herausstellt, je nachdem man Trypsin oder Pepsin zur Proteinspaltung benutzt. Wir werden dieses eigentümliche Verhältnis später eingehender besprechen.

Bevor wir zur Besprechung der eigentlichen Verdauungsversuche mit Proteinen übergehen, werden wir erst die Resultate einiger Versuche anführen, bei denen ca. $2 \%$ ige Lösungen von Pepsin oder Trypsin zur Selbstverdauung bei $37^{\circ}$ in den Thermostaten gestellt wurden, sowie einige Versuche, bei denen das Pepsin mit Trypsin und das Trypsin mit Pepsin verdaut wurde.

Aus der Tabelle geht hervor, daß das Pepsin selbst ca. 25\% formoltitrierbaren Stickstoffs enthält, was - wie aus den nachfolgenden Versuchen erhellen wird - Proteinen entspricht, die ca. 1 Monat der Wirkung von Pepsinsalzsäure ausgesetzt waren. Nach 32 tägigem Stehen im Thermostaten ist der formoltitrierbare Stickstoff von $24,8 \%$ auf $37,5 \%$ gestiegen, was zeigt, daß das «Pepsin» (oder vielmehr die im Präparat vorhandenen

1) V. Henriques und S. P. L. Sörensen, Diese Zeitschrift, Bd. 64. 


\section{Tabelle I.}

Selbstverdauung von Pepsin und Trypsin, Pepsinverdauung von Trypsin und Trypsinverdauung von Pepsin.

\begin{tabular}{|c|c|c|c|c|c|c|c|c|}
\hline & \multicolumn{5}{|c|}{$\begin{array}{l}\text { Formoltitrierung in } \\
\text { 4 Stadien; pro } 100 \mathrm{mg} \mathrm{N} \\
\text { wurden verbraucht } \mathrm{x} \mathrm{ccm} \\
1 / 5-\mathrm{n}-\mathrm{NaOH} ; \mathrm{x}=\end{array}$} & \multirow[t]{2}{*}{$\begin{array}{l}\text { Formol- } \\
\text { titrier- } \\
\text { barer } \mathrm{N} \\
\text { in } \% \text { des } \\
\text { Total- } \mathrm{N}\end{array}$} & \multirow{2}{*}{$\begin{array}{c}\text { Am- } \\
\text { moniak- } \\
\mathrm{N} \text { in } 0 / 0 \\
\text { des } \\
\text { Total-N }\end{array}$} & \multirow{2}{*}{$\begin{array}{c}1- \\
(4 \div K)\end{array}$} \\
\hline & 1. & 2. & 3. & 4. & $\mathbf{K}$ & & & \\
\hline Pepsin (Parke Da & 2,73 & 3,90 & 8,32 & 9,10 & 0,26 & 24,8 & 2,1 & $1-3,2$ \\
\hline Nach 32 tägiger Selbstverdauung . & 4,03 & 5,47 & 13,25 & 13,54 & 0,14 & 37,5 & 4,6 & $1-3,0$ \\
\hline Trypsinverdauung & 3,38 & 5,25 & 12,13 & 12,50 & 0,13 & 34,6 & - & $1-3,7$ \\
\hline Trypsin (Pankreatin, Rhe & 3,60 & 5,22 & 9,72 & 10,26 & 0,18 & 28,2 & 1,9 & $1-2,8$ \\
\hline Nach 33 tägiger Selbstverdauung . & 3,96 & 6,66 & 20,34 & 21,06 & 0,18 & 58,5 & 5,2 & $1-5,3$ \\
\hline Pepsinverdauung . & 5,25 & 7,80 & $|13,20|$ & $\mid 13,95$ & 0,15 & 38,6 & 5,1 & $1-2,6$ \\
\hline
\end{tabular}

Albumosen) sich bei «Selbstverdauung " in recht hohem Grade abbaut. Die Ammoniakbildung steigt von 2,1\% auf 4,6\% des Totalstickstoffs; diese Steigerung ist etwàs kleiner als die bei Pepsinverdauung von Proteinen gewöhnlich vorkommende. Bei Behandlung des Pepsins in neutraler Flüssigkeit mit Trypsin erhält man einen Abbau ähnlicher Art, wie der bei Selbstverdauung des Trypsins stattfindende (bemerke namentlich die letzte Kolonne $1-(4 \div \mathrm{K}))$.

Was das Trypsin betrifft, so enthält das Präparat selbst $28,2 \%$ formoltitrierbaren Stickstoff, einschließlich 1,9\% Ammoniakstickstoff. Bei 33 tägigem Stehen im Thermostaten bei $37^{\circ}$ steigert sich die Menge des formoltitrierbaren Stickstoffs auf 58,5\% (wovon 5,2\% Ammoniak-N). Die Wirkung ist also sehr intensiv und erinnert an die Spaltung von Hühnereiweiß durch Trypsin. Wird das Trypsin mit Pepsin-HCl behandelt, erhält man eine Spaltung, deren Art durchaus an die Selbstverdauung des Pepsins erinnert.

Auf das Verhältnis zwischen dem 1. und 4. Stadium werden wir später zurückkommen. 


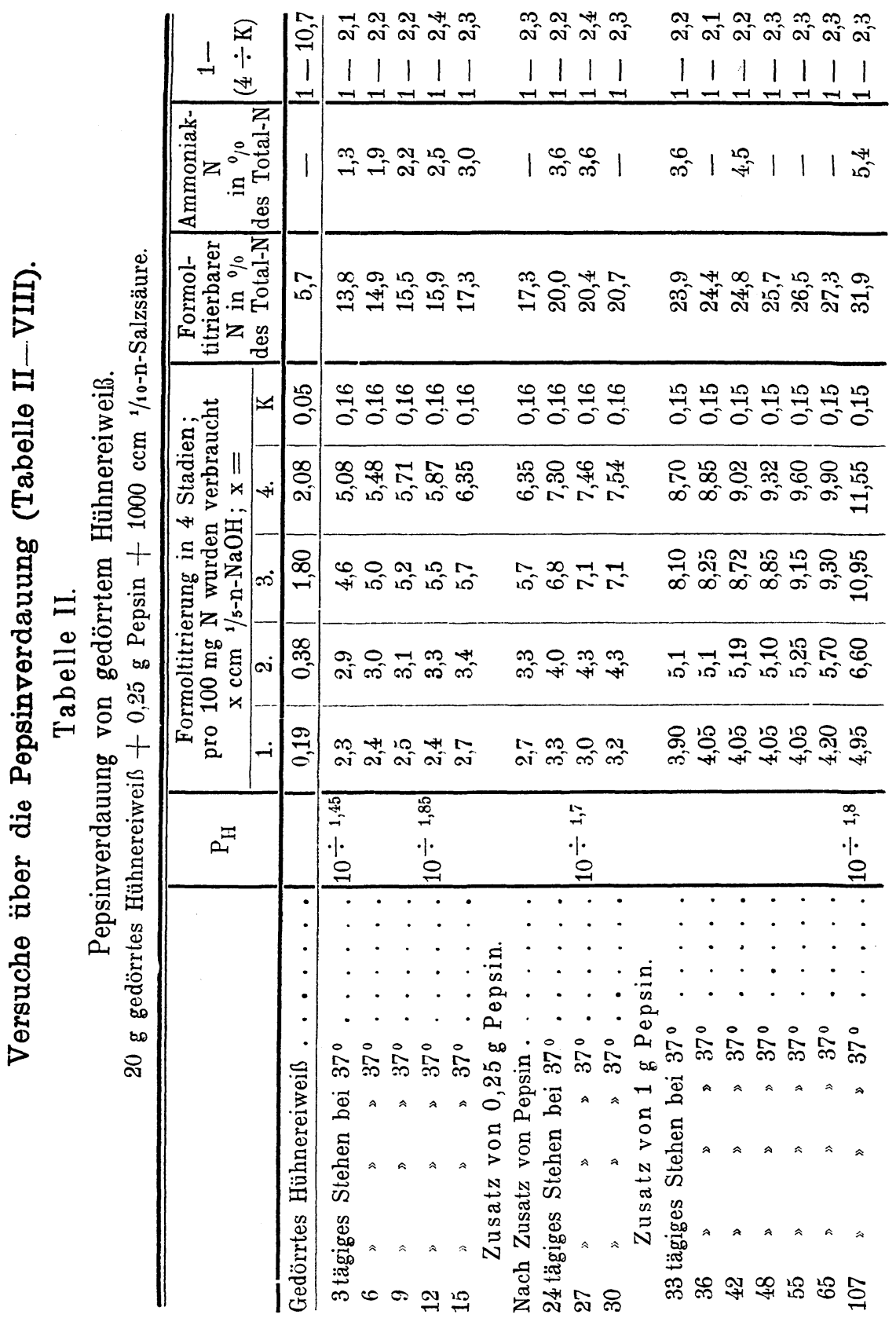


Über hydrolytische Spaltungen von Proteinen.

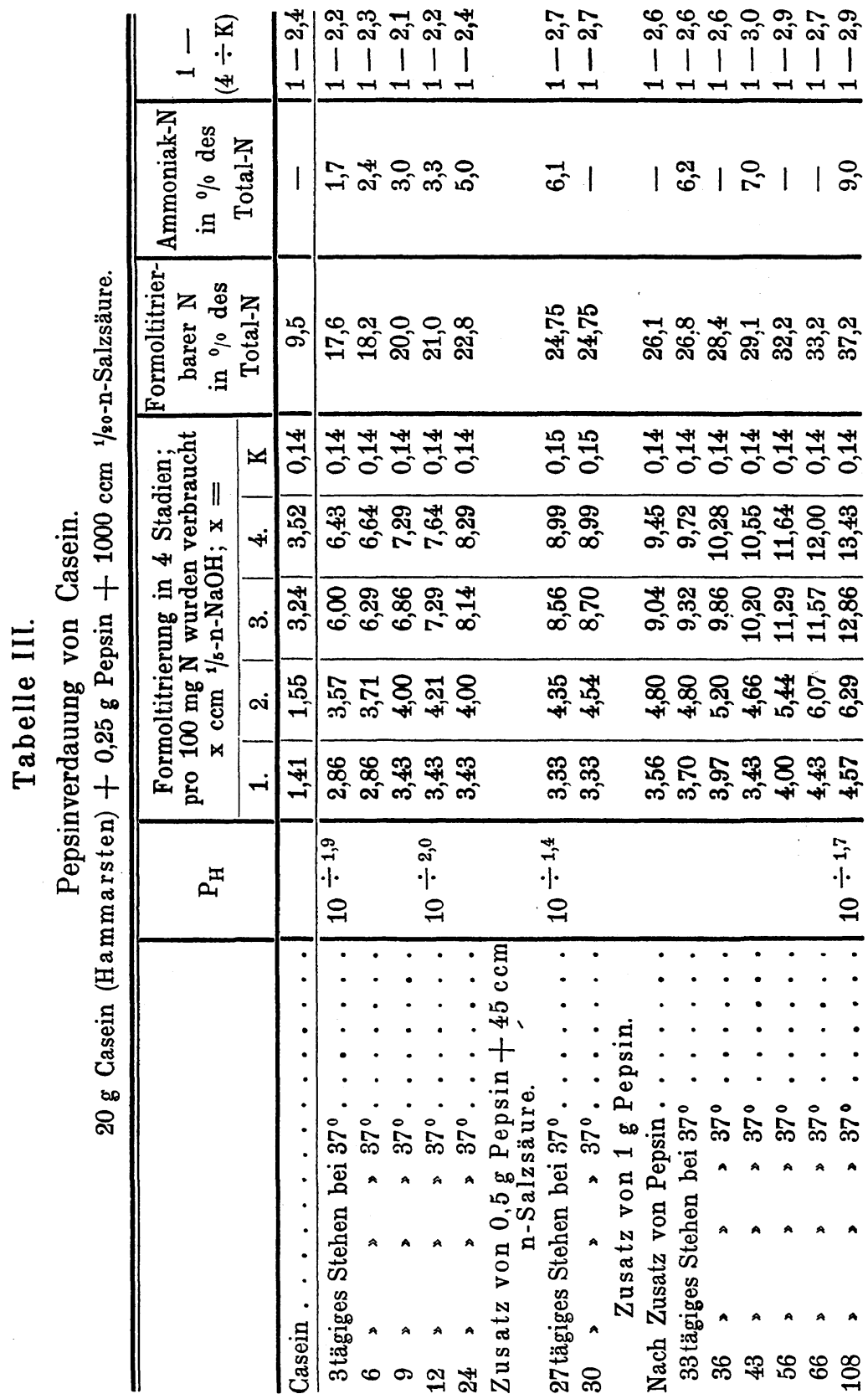

Hoppe-Seyler's Zeitschrift f. physiol. Chemie. LXXV. 


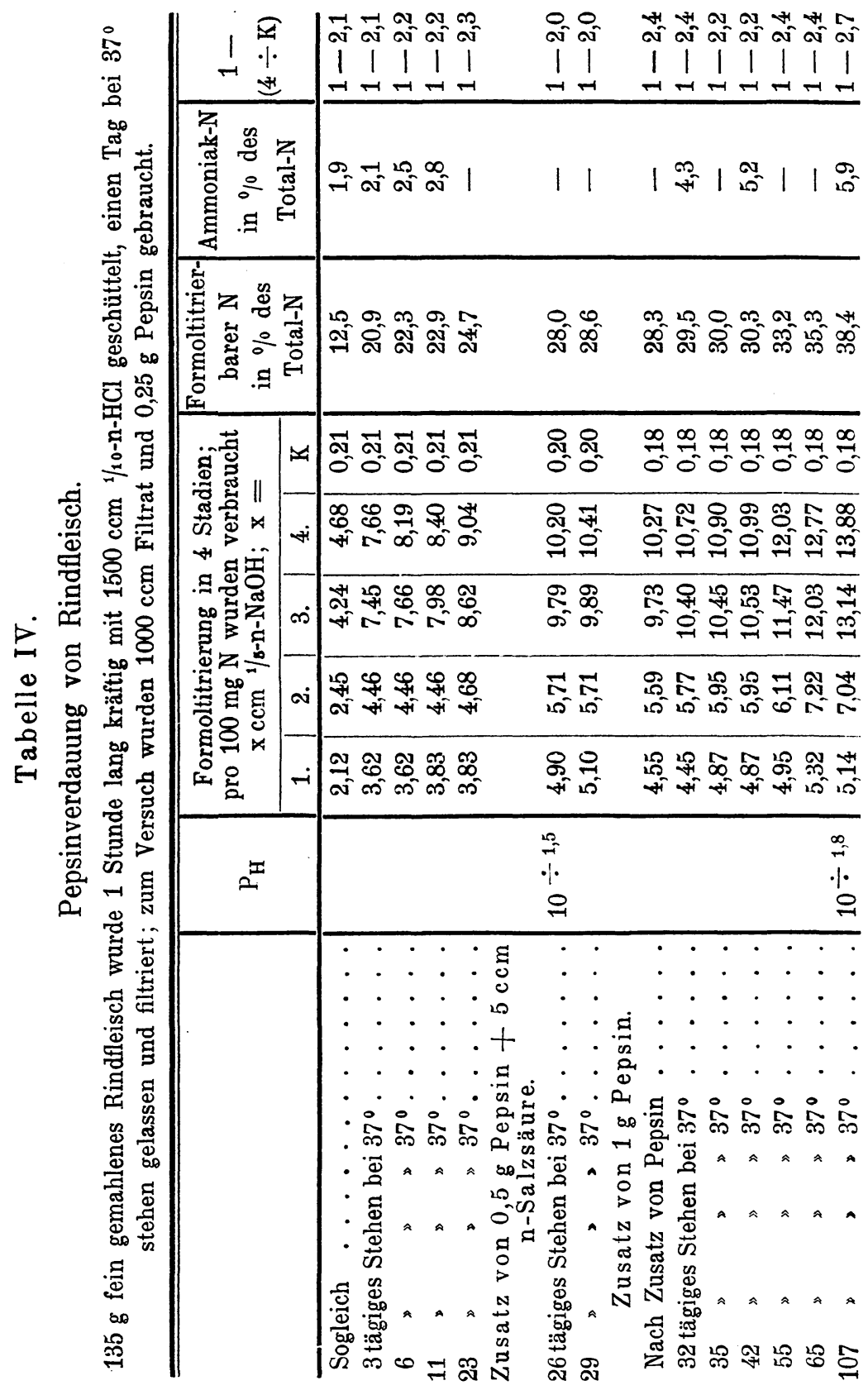


Über hydrolytische Spaltungen von Proteinen.

\begin{tabular}{|c|c|c|c|c|c|c|}
\hline & 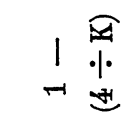 & & $\stackrel{0}{-1}$ & 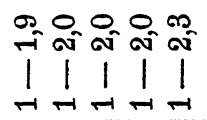 & 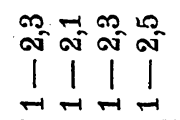 & 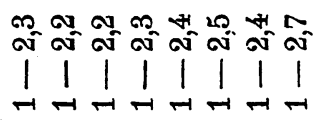 \\
\hline & 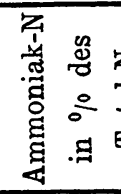 & & 1 & 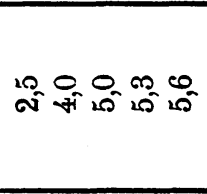 & $11 \stackrel{0}{\approx} 1$ & $1 \approx 1 \stackrel{\infty}{\infty}|1| \infty_{\infty}^{\infty}$ \\
\hline & 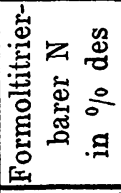 & & $\stackrel{s}{*}$ & 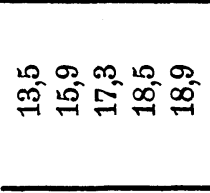 & 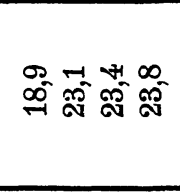 & 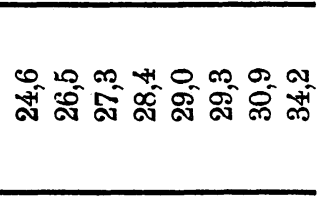 \\
\hline 疍 & 泀 & $\approx$ & 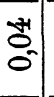 & 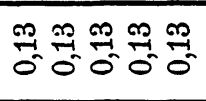 & 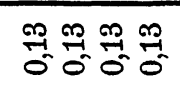 & 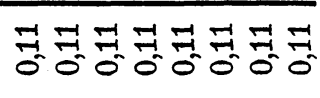 \\
\hline 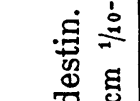 & 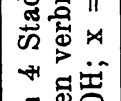 & $|+i|$ & 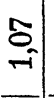 & 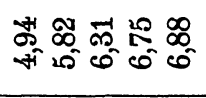 & 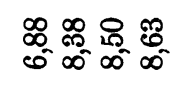 & 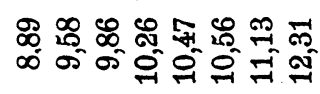 \\
\hline 도용 & 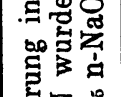 & $\infty$ & $\stackrel{8}{\circ}$ & 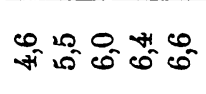 & 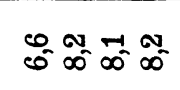 & 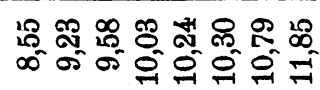 \\
\hline 我十 & 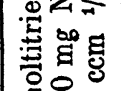 & ii & 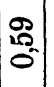 & min & 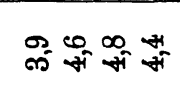 & 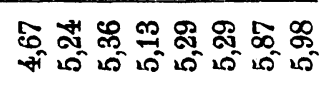 \\
\hline مَ & 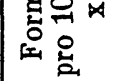 & $-i$ & : & 워 & Os कs & 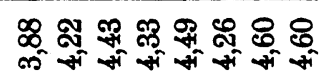 \\
\hline $\begin{array}{r}.0 \\
0 \\
0 \\
0 \\
0 \\
0 \\
0 \\
. \Xi\end{array}$ & Dir & & & $\begin{array}{ll}* & \approx \\
\% & \% \\
\circ & 0\end{array}$ & $\begin{array}{l}3 \\
1.1 \\
0 \\
0\end{array}$ & $\begin{array}{l}\stackrel{0}{*} \\
\% \\
0\end{array}$ \\
\hline s & & & 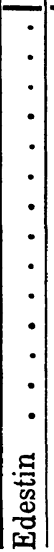 & 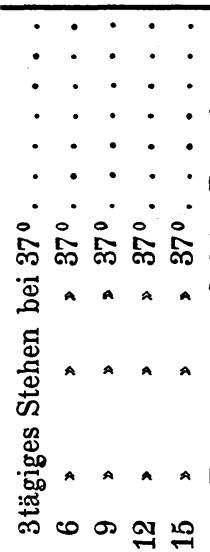 & 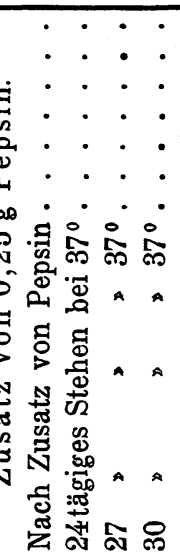 & 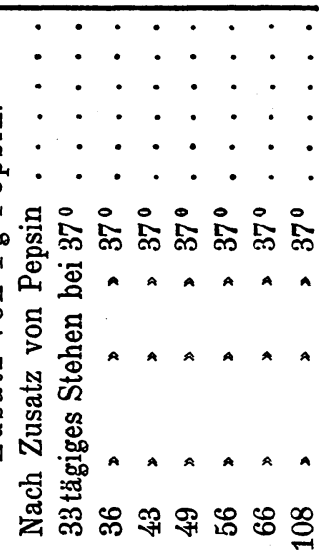 \\
\hline
\end{tabular}




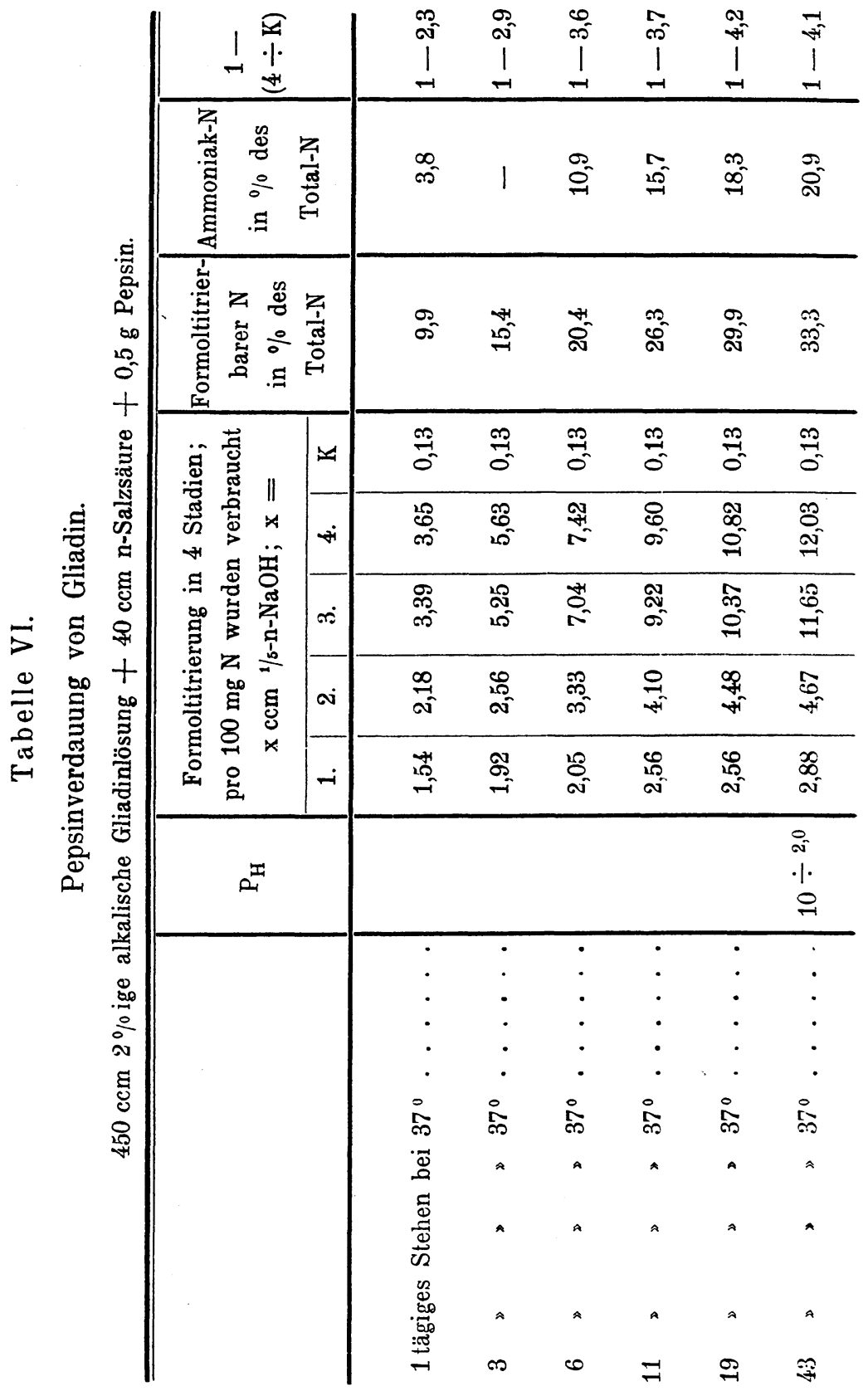


Über hydrolytische Spaltungen von Proteinen.

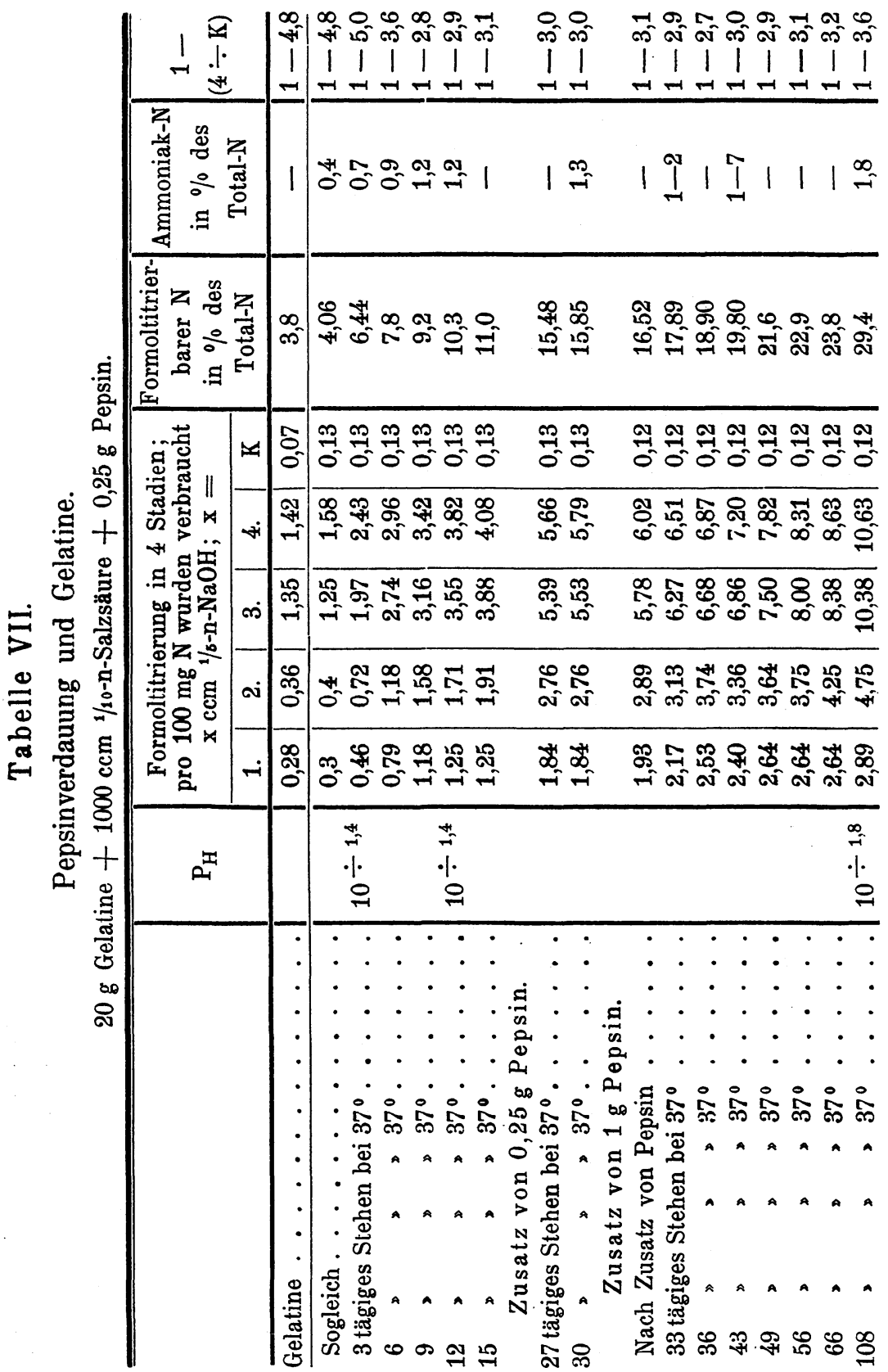




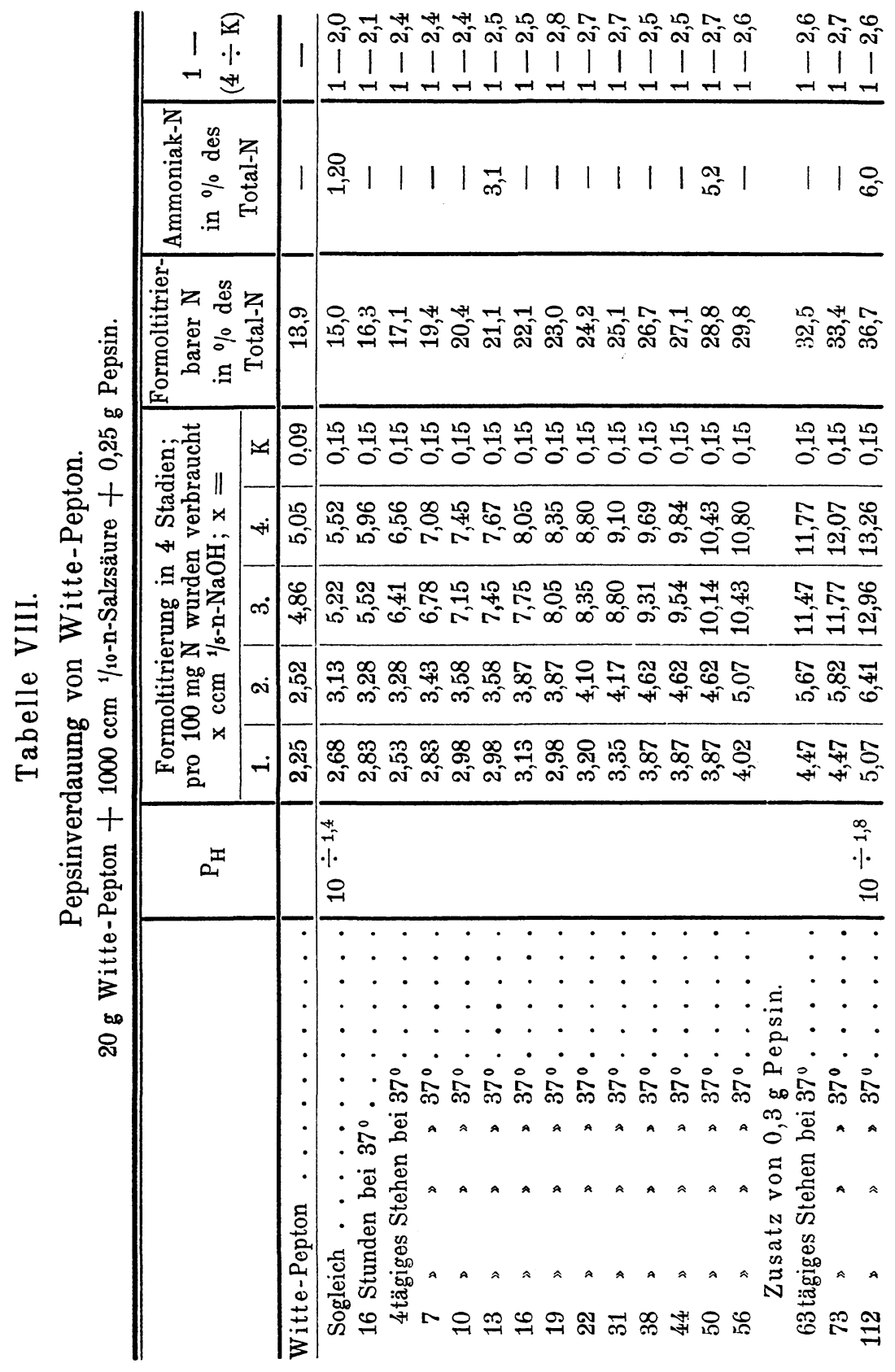


Betrachten wir zuerst den Grad des Abbaus, so erhält man am leichtesten einen Überblick darüber durch folgenden Auszug aus den Tabellen.

\begin{tabular}{c|c|c}
\hline $\begin{array}{c}\text { Das angewandte } \\
\text { Protein }\end{array}$ & $\begin{array}{c}\text { Dauer des Versuches } \\
\text { in Tagen }\end{array}$ & $\begin{array}{c}\text { Formoltitrierbarer N } \\
\text { in \% des Total-N }\end{array}$ \\
\hline Hühnereiweiß . . & 107 & 31,9 \\
Casein..... . & 108 & 37,2 \\
Mageres Rindfleisch & 107 & 38,4 \\
Edestin . . . . & 108 & 34,2 \\
Gliadin...... & 43 & 33,3 \\
Gelatine . . . . & 108 & 29,4 \\
Witte-Pepton . . & 112 & 36,7
\end{tabular}

Wie man sieht, ist der Abbau am größten beim Rindfleisch, indem man hier nach 107 Tagen 38,4\% formoltitrierbaren Stickstoffs erreicht hat; eine fast ebenso weitgehende Spaltung wurde in ungefähr derselben Zeit bei folgenden Stoffen erreicht: Casein $(37,2 \%)$, Witte-Pepton $(36,7 \%)$, Hühnereiweiß $(31,9 \%)$ und Edestin $(34,2 \% \%)$, während die Gelatine mit 29,4\% am niedrigsten steht. Für das Gliadin wurde die Verdauung nur 43 Tage lang untersucht. Die Spaltung erreichte hier doch $33,3 \%$; die Bedeutung davon ist aber weniger leicht übersehbar wegen der ungemein großen Ammoniakabspaltung während der Verdauung.

Betrachtet man den Verlauf der Hydrolyse näher, so scheint die Pepsinwirkung selbst nach einiger Zeit sehr stark abzunehmen oder vielleicht ganz aufzuhören, und die darauffolgende, langsam, aber kontinuierlich fortschreitende Hydrolyse beruht also (siehe die späteren Versuche mit Säurewirkung auf die Proteine) ausschließlich auf der Einwirkung der vorhandenen Salzsäure. Wird darauf neues Pepsin zugesetzt, verläuft die Spaltung wieder schneller, um danach wieder abzunehmen, bis neue Fermentlösung zugesetzt wird. Es ist somit nicht unangemessen, anzunehmen, daß man bei viel häufigerem $\mathrm{Zu}$ satz von frischem Pepsin, als in unseren Versuchen, imstande wäre - im Laufe der obengenannten Zeit von ca. 107 Tagen - 
die Hydrolyse beträchtlich weiter zu bringen, als wir in unseren Versuchen. Indessen wird es immer bei sehr langwierigen Versuchen mit Pepsinsalzsäure schwer sein, zu entscheiden, wieviel von der Spaltung der Pepsinwirkung und wieviel der Säurewirkung zuzuschreiben ist. Wenn man durch jahrelange Einwirkung von Pepsinsalzsäure (oder Pepsinschwefelsäure) eine Abspaltung freier Aminosäuren ${ }^{1}$ ) in größeren Mengen erzielt hat, so darf man annehmen, daß man hier mit einer Säurewirkung $\mathrm{zu}$ schaffen hat, und daß das Pepsin in der Beziehung keine Rolle spielt.

Wie erwähnt, ist der Abbau bei den verschiedenen Proteinen durch die Pepsinsalzsäurewirkung nach ca. 107 Tagen so weit vorgeschritten, daß ca. $35 \%$ des Totalstickstoffs formoltitriert werden können. Dieses Verhältnis gibt uns indessen keinen Aufschluß über die Art der hydrolytischen Spaltung, und namentlich läßt sich nicht entscheiden, ob durch die Pepsinwirkung eine Abspaltung freier Aminosäuren stattfindet. Um zu untersuchen, ob das Pepsin imstande ist, eine solche Abspaltung zu erzeugen, fällten wir eine Lösung von Pepsin- $\mathrm{H}_{2} \mathrm{SO}_{4}$-verdautem Witte-Pepton, die $25 \%$ formoltitrierbaren Stickstoffs enthielt, mit Phosphorwolframsäure.

$800 \mathrm{ccm}$ der Lösung mit einem Totalstickstoffgehalt von $2,192 \mathrm{~g}$ wurden in 3\% iger schwefelsaurer Lösung mit Phosphorwolframsäure gefällt. Das Filtrat der Fällung wurde nach Entfernung des Überschusses an Phosphorwolframsäure und Schwefelsäure bis zu $100 \mathrm{ccm}$ eingedämpft; $5 \mathrm{ccm}$ davon enthielten 15,1 mg N; im Filtrat der Phosphorwolframsäurefällung fanden sich somit nur 13,8\% des Totalstickstoffs. Im Rest des Filtrats wurde nun Formoltitrierung vorgenommen, teils sogleich, teils nach totalem Abbau im Autoklaven mit $3 \mathrm{n}-\mathrm{HCl}\left(1^{1 / 2}\right.$ Stunden bei $150^{\circ}$ ) und darauffolgender Entfärbung mit $\left.\mathrm{AgNO}_{3} .{ }^{2}\right)$ Die nach vorhergehender Lackmusneutralisation in Stadien ange-

1) L. Langstein, Zur Kenntnis der Endprodukte der peptischen Verdauung, Hofmeisters Beiträge, Bd. 1 u. 2.

2) S. P. L. Sörensen und H. Jessen-Hansen, Über die Ausführung der Formoltitrierung in stark farbigen Flüssigkeiten, Biochem. Zeitschrift, Bd. 7. 
stellte Formoltitrierung fand in einer $25 \mathrm{ccm}$ des eingedampften Filtrats entsprechenden Menge statt. Das Resultat war:

Vor der Spaltung:

Nach totaler Spaltung im Autoklaven:

$$
1 .
$$

2.

3.

4.

$$
\left.\begin{array}{l}
4,4-5,5-10,2-10,5 \\
2,0-3,6-17,1-17,9
\end{array}\right\} \mathrm{K}=0,1 \text {. }
$$

Da der Totalstickstoff in $25 \mathrm{ccm} 75,5 \mathrm{mg}$ betrug, fanden sich also vor der Spaltung 38,6\% formoltitrierbaren Stickstoffs und nach totaler Spaltung $66 \%$ (wovon 7,2\% Ammoniakstickstoff). Aus diesen Zahlen wird hervorgehen, daß das Filtrat eine bedeutende Menge «peptidgebundenen» Stickstoffs enthielt, weshalb es nicht lauter freie Aminosäuren enthalten haben kann. Es zeigte sich jedoch, daß die Flüssigkeit freies Tryptophan enthielt, indem man durch Bromwasser eine sehr starke Reaktion erhielt, weshalb man zu dem Schlusse berechtigt sein muß, daß diese Aminosäure durch Einwirkung von Pepsinsäure von Proteinen abgespaltet werden kann. Ob außer Tryptophan andere freie Aminosäuren durch die Einwirkung des Pepsins abgespaltet werden, haben wir nicht untersucht, aber die geringe Menge Stickstoff im Filtrat der Phosphorwolframsäurefällung deutet darauf, daß die Menge solcher freien Säuren jedenfalls sehr gering sein muß.

Wir werden hier die früheren Untersuchungen über die Pepsinverdauung keiner näheren Besprechung unterziehen, sondern nur aut Zunz's ${ }^{1}$ ) Untersuchungen aufmerksam machen, die dargetan haben, daß sich bei der Pepsinverdauung bereits im Laufe verhältnismäßig kurzer Zeit bis 60\% Stickstoff abspalten in einer Form, die keine Biuretreaktion gibt. Was die Abspaltung von Aminosäuren -- darunter auch die divergierenden Angaben über die Abspaltung von Tryptophan - betrifft, verweisen wir auf Arbeiten von Pfaundler, ${ }^{2}$ ) Salaskin, ${ }^{3}$ ) D. Lawrow ${ }^{4}$ ) und Malfatti. ${ }^{5}$ )

1) E. Zunz, Diese Zeitschrift, Bd. 28, und Hofmeisters Beiträge, $\mathrm{Bd} .2$.

2) M. Pfaundler, Diese Zeitschrift, Bd. 30.

$\left.{ }^{3}\right)$ S. Salaskin, Diese Zeitschrift, Bd. 32.

4) D. Lawrow, Diese Zeitschrift, Bd. 33.

5) Malfatti, Diese Zeitschrift, Bd. 31. 
Ein Verfahren, das, wie es sich zeigt, wertvolle Aufschlüsse über die Art der hydrolytischen Spaltung gibt, ist die oben erwähnte Formoltitrierung in 4 Stadien. Werden $20 \mathrm{ccm}$ einer Lösung von $\left.n / 10-G_{1 y c i n}{ }^{1}\right)$ titriert, findet man, daß eine lackmusneutrale, Phenolphthalein enthaltende Lösung durch Zusatz von $0,2 \mathrm{ccm} \mathrm{n} / \overline{5}-\mathrm{NaOH}-L o ̈ s u n g$ schwach rot, bei $0,9 \mathrm{ccm}$ stark rot wird. Wird danach neutrale Formollösung zugesetzt, muß man 9,88 ccm zusetzen, um die stark rote Farbe der Kontrollösung zu erreichen. Benutzt man dagegen statt der Glycinlösung $20 \mathrm{ccm}$ n/20-Lösung von Glycylglycin, stellt sich die Sache ganz anders, indem zum 1. Stadium der Titrierung $2,25 \mathrm{ccm} \mathrm{n/5}-\mathrm{NaOH}$, zum 2. Stadium $4,0 \mathrm{ccm}$ und schließlich zum 4 . Stadium $4,9 \mathrm{ccm}$ verbraucht werden. Berechnen wir nun das Verhältnis zwischen dem 1. und dem 4. Stadium (das in den Tabellen als $1-(4 \div \mathrm{K})$ bezeichnete), so ist dies für das Glycin $=1-48,9$, für das Glycylglycin aber 1-2,1. Das Glycin und das Glycylglycin weisen also in dieser Beziehung einen sehr großen Unterschied auf. Wie sich andere Di- oder Polypeptide bei Formoltitrierung in Stadien verhalten, hatten wir keine Gelegenheit zu untersuchen; vieles deutet aber darauf hin, daß diese Verbindungen sich in allem Wesentlichen wie Glycylglycin verhalten. Was andere Aminosäuren als das Glycin betrifft, haben wir einige Titrierungen unternommen, deren Ergebnisse in Tabelle IX angeführt sind.

Aus den Versuchsresultaten der Tabelle IX, die durch Formoltitrierung lackmusneutralisierter Lösungen der angeführten Aminosäuren gewonnen wurden, wird erhellen, daß das 1. Stadium der Formoltitrierung, was das Arginin, Lysin, Tryptophan und Cystin betrifft, verhältnismäßig größer ist als das des Glycins, aber doch bei weitem nicht so groß wie das des Glycylglycins; das Verhältnis $1-(4 \div \mathrm{K})$ schwankte bei den angeführten Aminosäuren von $1-6,8$ bis $1-11,5$. Das Leucin ähnelt ganz dem Glycin. Was die Aminodicarbonsäuren betrifft, so sieht man, daß das 1. Stadium hier sehr kurz, gar kürzer ist als beim Glycin, indem das Verhältnis $1-(4 \div \mathrm{K})$

1) Siehe V. Henriques und S. P. L. Sörensen, a. a. O. 
Tabelle IX.

Formoltitrierung in 4 Stadien von einigen Aminosäuren in lackmusneutraler Lösung.

\begin{tabular}{|c|c|c|c|c|c|c|c|c|}
\hline & \multirow{2}{*}{$\begin{array}{l}\text { Total-N } \\
\text { in } \mathrm{mg}\end{array}$} & \multicolumn{5}{|c|}{$\begin{array}{l}\text { Formoltitrierung in } \\
4 \text { Stadien: Verbrauchte } \\
\text { Anzahl ccm } 1 / 5-\mathrm{n}-\mathrm{NaOH}\end{array}$} & \multirow{2}{*}{$\begin{array}{l}\text { Formol- } \\
\text { titrier- } \\
\text { barer N } \\
\text { in } \% \text { des } \\
\text { Total-N }\end{array}$} & \multirow[t]{2}{*}{$\begin{array}{c}1- \\
(4 \div \mathrm{K})\end{array}$} \\
\hline & & 1. & 2. & 3. & 4. & $\mathrm{~K}$ & & \\
\hline Arginin . . . & 100 & ,21 & 2,11 & 8,11 & 8,37 & 0,15 & 23,0 & $1-6,8$ \\
\hline Lysin . • & 100 & 3,00 & 4,35 & 33,00 & 34,50 & 0,25 & 95,9 & $1-11,5$ \\
\hline Histidinchlorid ') & 100 & 8,97 & 10,35 & 13,11 & 17,02 & 0,23 & 50,8 & $1-$ \\
\hline Histidin ${ }^{1}$ ) & 100 & 6,94 & 8,18 & 11,42 & 15,68 & 0,22 & 43,8 & $1-2,2$ \\
\hline Asparaginsäure. & 100 & 0,21 & 1,22 & 30,75 & 34,03 & 0,41 & 94,1 & $1-162$ \\
\hline Glutaminsäure & 100 & 0,18 & 2,00 & 31,67 & 34,94 & 0,36 & 9 & $1-194$ \\
\hline Leucin . & 100 & 0,53 & 1,40 & 32,90 & 34,30 & 0,35 & 95,1 & $1-64,7$ \\
\hline Tryptophan & 100 & 1,86 & 2,79 & 14,26 & 15,69 & 0,31 & 43,1 & $1-$ \\
\hline Gystin . . . & 10 & 0,338 & 1,11 & $2,77_{5}$ & $2,88_{6}$ & $0,11_{1}$ & 77,7 & $1-$ \\
\hline
\end{tabular}

hier für Asparaginsäure 1-162 und für Glutaminsäure 1-194 betrug. Ein merkwürdiges Verhältnis offenbart das Histidin, indem $1-(4 \div \mathrm{K})$ hier $1-1,9$ beträgt; das 1 . Stadium ist hier also länger als beim Glycylglycin. Durchsieht man ferner die verschiedenen Stadien beim Histidin, so entdeckt man das merkwürdige Verhältnis, daß, während der Abstand zwischen dem 1. und 2. Stadium (d. h. zwischen schwach und stark roter Farbe vor dem Formolzusatz) kurz ist, der Abstand zwischen dem 3. und 4. Stadium (d. h. zwischen schwach und stark roter Farbe nach dem Formolzusatz) 2-3 mal so groß ist. Es wird sich indessen zeigen, daß das 1 . Stadium der Formoltitrierung bei den freien Aminosäuren durchgehends kurz ist.

Als Resultat des hier Angeführten können wir also feststellen, daß in allen den Fällen, wo sich bei Hydrolyse eines Proteinstoffes eine große Menge freier Aminosäuren bildet, das Verhältnis zwischen dem 1. und 4. Stadium weit sein wird, während das Verhältnis eng sein wird, wenn sich bei der Hydro-

1) Lackmusneutralisation schwierig. 
lyse keine freien Aminosäuren, dagegen mehr oder weniger kompliziert gebaute Polypeptide (oder nur Dipeptide) bilden.

Betrachten wir, eingedenk dieses Verhältnisses, die Kolonne $1-(4 \div \mathrm{K})$ der oben mitgeteilten Versuche über die Pepsinwirkung, so sehen wir, daß sich das gesamte Verhältnis in fast allen Versuchen nur wenig ändert, allmählich wie die Verdauung fortschreitet; jedoch ist das Resultat nicht ganz das gleiche bei allen untersuchten Proteinen. Beim Witte-Pepton war das Verhältnis $1-(4 \div \mathrm{K})$ zu Anfang des Versuches $1-2,0$ (einem Gehalt von 15\% formoltitrierbarem N entsprechend); nach nur 4 Tagen beträgt das Verhältnis $1-2,4$; nach 19 Tagen 1-2,8, worum das Verhältnis nun ohne nennenswerte Abänderung schwankt, trotzdem die Hydrolyse noch immer fortschreitet (was aus den Zahlen der Menge von formoltitrierbarem $\mathrm{N}$ deutlich hervorgeht).

Eine ähnliche, nur wenig fortschreitende Abänderung des Verhältnisses $1-(4 \div K)$ findet man auch bei den Versuchen mit Gelatine, Edestin, Rindfleisch und Casein. Beim Gliadin ist die Abweichung größer, indem das Verhältnis $1-(4 \div \mathrm{K})$ nach 1 tägiger Verdauung $1-2,3$ beträgt (mit $9,9 \%$ formoltitrierbarem $\mathrm{N}$ ), und nach 43 Tagen $1-4,1$ erreicht hat (mit $33,3 \%$ formoltitrierbarem $\mathrm{N}$ ); da indessen hier außerordentlich viel Ammoniak abgespaltet wird (über die Hälfte des formoltitrierbaren $\mathrm{N}$ ist als Ammoniak abgespaltet), und da das Verhältnis $1-(4 \div \mathrm{K})$ bei Ammoniak weit $\left.{ }^{1}\right)$ ist, läßt das Gliadin sich nicht direkt mit den übrigen Proteinen vergleichen.

Eigentümlich ist, daß die Verdauung des Hühnereiweißes von der der übrigen untersuchten Proteine abweicht, wenn die Abweichung auch nicht besonders groß ist. Betrachten wir das Verhältnis $1-(4 \div \mathrm{K})$ beim Hühnereiweiß, so sehen wir, daß dies sich nach wenig Tagen auf eine Größe einstellt, die zwischen 1-2,2 und 1-2,4 schwankt, und daß dieses Verhältnis unverändert bleibt, trotzdem die Hydrolyse in stetem Fortschritt ist (formoltitrierbarer $\mathrm{N}$ steigt von ca. 14\% auf ca. $32 \%$ ).

1) V. Henriques und S. P. L. Sörensen, a. a. O. 
Wir sehen also, daß das Verhältnis $1-(4 \div \mathrm{K})$ sich bei Pepsinverdauung verschiedener Proteine nach wenig Tagen auf eine zwischen 1-2,0 und 1-3,0 liegende Größe einstellt (mit Ausnahme des Gliadins ${ }^{1}$ )). Wenn wir uns nun erinnern, daß das genannte Verhältnis beim Glycin 1-48,9 und daß dasselbe Verhältnis bei anderen Aminosäuren (mit Ausnahme des Histidins) gleichfalls' sehr weit ist, während es bei Glycylglycin sehr eng ist, nämlich 1-2,1, so scheint es berechtigt, aus den bei der Pepsinverdauung gefundenen Zahlen zu schließen, daß die spaltende Wirkung des Pepsins auf keiner nennenswerten Abspaltung von Aminosäuren beruhen kann, sondern auf einer Spaltung beruhen muß, bei der sich beständig - sogar bei stark vorgeschrittener Verdauung - Di- oder Polypeptide bilden. Wie wir unten eingehender besprechen werden, stellt das Verhältnis sich ganz anders, wenn von der Einwirkung des Trypsins auf Proteine die Rede ist.

Was die Ammoniakbildung bei der Pepsinverdauung betrifft, so wird aus den Tabellen erhellen, daß die Ammoniakmenge beständig zunimmt, allmählich wie der Abbau fortschreitet. Ferner sieht man, daß die verschiedenen Proteine sehr variierende Mengen Ammoniak abspalten, was aus untenstehender Übersicht über die Ammoniakmenge (Ammoniak-N in Prozent des Total-N) bei den untersuchten Proteinen zu Ende der Verdauung deutlich hervorgeht. Diese dauerte bei den meisten Stoffen 104 Tage; das Witte-Pepton wurde 112 Tage, das Gliadin nur 43 Tage verdaut.

$$
\begin{aligned}
& \text { Hühnereiwei }=5,4 \% \text {; Gliadin } \quad=20,9 \% \text {; } \\
& \text { Casein } \quad=9,0 \% \text {; Gelatine } \quad=1,8 \% \text {; } \\
& \text { Edestin } \quad=8,70 \% \text {; Witte-Pepton }=6,0 \% \text {. }
\end{aligned}
$$

Während Gelatine nur sehr wenig Ammoniak abspaltet, spaltet dahingegen ein Stoff wie das Gliadin große Ammoniakmengen $a b$ (über $1 / 5$ des Gesamtstickstoffs). Bei den übrigen untersuchten Proteinen schwankt die Ammoniakmenge zwischen $5,4 \%$ und 9,0\% des Gesamtstickstoffs. Die Ammoniakbildung

1) Bei den verschiedenen genuinen Proteinstoffen schwankt das Verhältnis $1-(4-K)$; siehe V. Henriques und J. K. Gjaldbæk, Diese Zeitschrift, Bd. 71 . 
bei Einwirkung von Pepsin-Salzsäure ist also eine recht bedeutende $^{1}$ ) und, wie wir später sehen werden, viel größer als bei Einwirkung von Trypsin.

Versuche über die Trypsinverdauung. (Tab. X-XV.)

Wie aus den Tabellen hervorgeht, wurden bei den Versuchen über die Trypsinverdauung dieselben Proteine benutzt wie bei der Pepsinverdauung. Die Dauer der Verdauung betrug zwischen 40 und 73 Tagen, und es wurde im Laufe dieser Zeit neue Trypsinlösung zugesetzt, wenn der Prozeß fast ins Stocken geraten war: gewöhnlich wurde 2 mal im Laufe jedes Versuches Trypsin zugesetzt.

Die Größe des Abbaus bei Trypsineinwirkung ergibt sich als höchst verschieden bei den verschiedenen Proteinen. Eine direkte Vergleichung läßt sich wohl kaum anstellen, da die Dauer der Versuche nicht überall die gleiche ist: wie aus untenstehender Übersicht über die gewonnenen Resultate ersichtlich ist, machten sich große Unterschiede geltend. Die Übersicht enthält vergleichshalber die Menge von formoltitrierbarem Stickstoff, der sich bei der Pepsinverdauung sowie bei Totalspaltung der Proteine bei Erwärmung mit $3 \mathrm{n}-\mathrm{HCl}$ im Autoklaven $1 \frac{1}{1 / 2}$ Stunden auf $150^{\circ}$ bildet.

\begin{tabular}{|c|c|c|c|c|}
\hline \multirow{2}{*}{$\begin{array}{c}\text { Der untersuchte } \\
\text { Proteinstoff }\end{array}$} & \multirow{2}{*}{$\begin{array}{l}\text { Die Dauer } \\
\text { der Trypsin- } \\
\text { verdauung } \\
\text { in Tagen }\end{array}$} & \multicolumn{3}{|c|}{ Formoltitrierbarer $\mathrm{N}$ in $\%$ des Total- $\mathrm{N}$ be } \\
\hline & & $\begin{array}{l}\text { Trypsin- } \\
\text { verdauung }\end{array}$ & $\begin{array}{l}\text { Pepsin- } \\
\text { verdauung }\end{array}$ & $\begin{array}{l}\text { Total- } \\
\text { spaltung }\end{array}$ \\
\hline Hühnereiweiß . & 73 & 60,2 & 31,9 & 83,6 \\
\hline Casein . & 73 & 42,5 & 37,2 & 83,4 \\
\hline Edestin . . & 40 & 45,4 & 34,2 & 70,9 \\
\hline Gliadin . . & 43 & 35,5 & 33,3 & 79,1 \\
\hline Gelatine . . . & 71 & 25,0 & 29,4 & 86,3 \\
\hline Witte-Pepton & 73 & 43,1 & 36 & 77,9 \\
\hline
\end{tabular}

1) Vgl. E. Zunz, Weitere Untersuchungen über den Verlauf der peptischen Eiweißspaltung, Hofmeisters Beiträge, Bd. 2. 
Über hydrolytische Spaltungen von Proteinen.

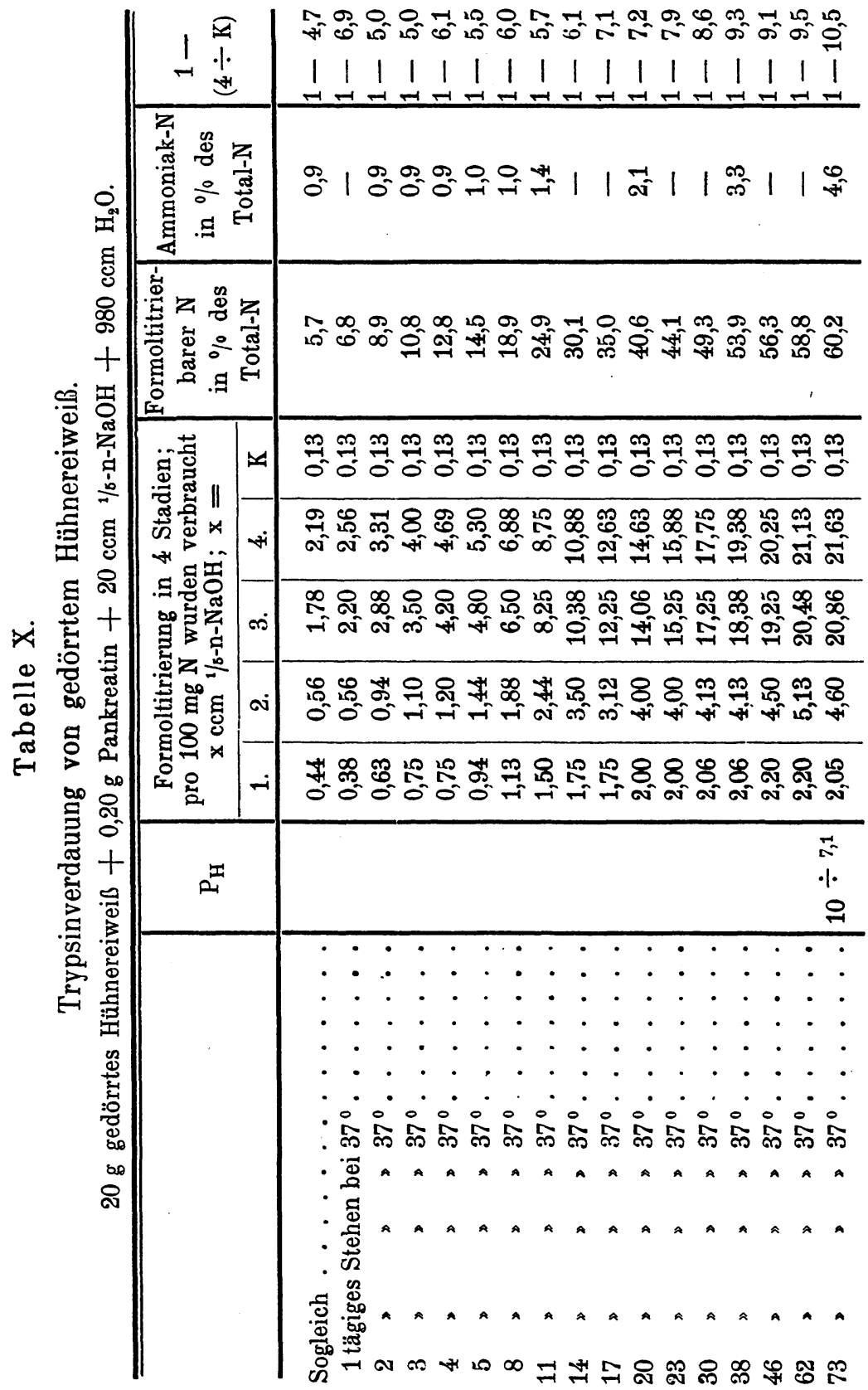


V. Henriques und J. K. Gjaldbæk,

\begin{tabular}{|c|c|c|c|c|c|c|}
\hline & $\begin{array}{r}1 \\
1 \\
-1\end{array}$ & & 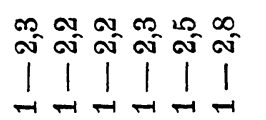 & 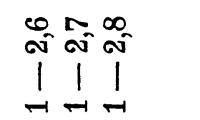 & 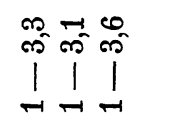 & 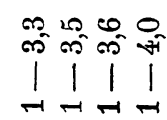 \\
\hline & 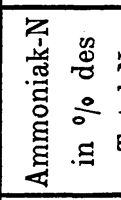 & & $\tilde{\sigma}=1 \stackrel{m}{=}$ & $1 \cong 1$ & के 11 & $0_{20}^{0} 11 . \overrightarrow{20}$ \\
\hline 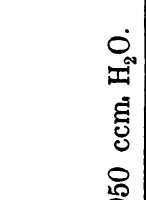 & 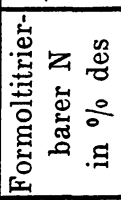 & & 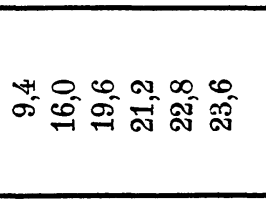 & 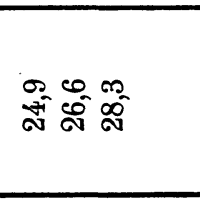 & 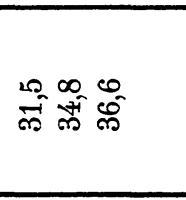 & 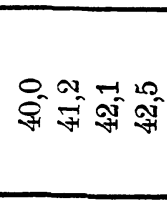 \\
\hline $\begin{array}{l}\text { के } \\
+ \\
\tau\end{array}$ & 节 & 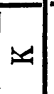 & 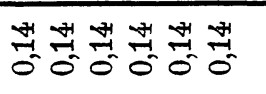 & 送 & $\frac{20}{9} \frac{12}{0} \frac{12}{0}$ & 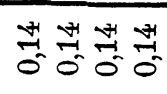 \\
\hline 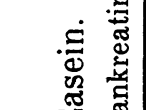 & 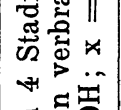 & +4 & 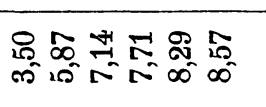 & 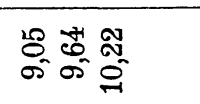 & 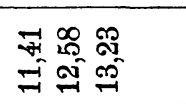 & 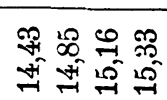 \\
\hline $\begin{array}{ccc} & 0 & 0 \\
& 0 & 0 \\
& 0 & 0\end{array}$ & 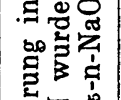 & $\infty$ & 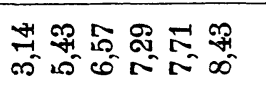 & 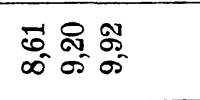 & 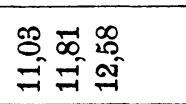 & 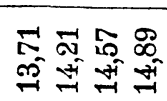 \\
\hline $\begin{array}{ll}0 & 0 \\
\vdots & \Xi\end{array}$ & 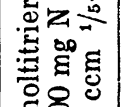 & oi & 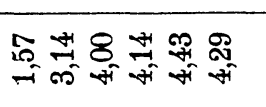 & 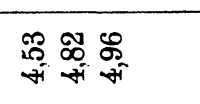 & 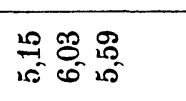 & 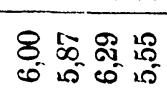 \\
\hline 崩 & 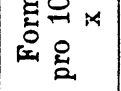 & $-i \mid$ & 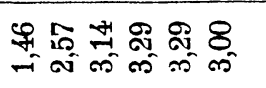 & 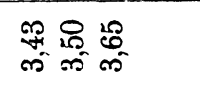 & 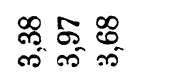 & 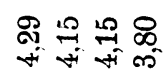 \\
\hline 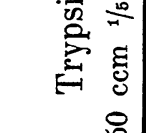 & 2 & & & & & $\stackrel{-}{\theta}$ \\
\hline .5 & & & 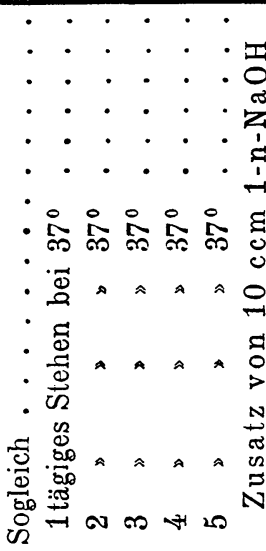 & 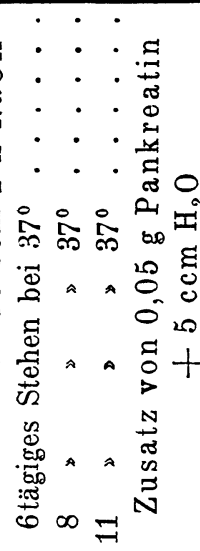 & 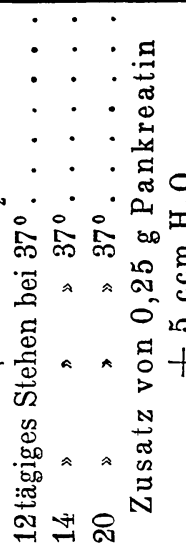 & 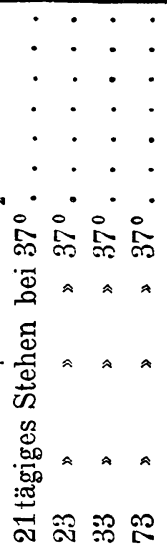 \\
\hline
\end{tabular}


Uber hydrolytische Spaltungen von Proteinen.

385

\begin{tabular}{|c|c|c|c|c|c|c|c|}
\hline & $\begin{array}{r}1 \\
1 \% \\
+4\end{array}$ & & $\begin{array}{ccc}0 & 0 \\
0 & 0 \\
1 & 0 \\
1 & 1\end{array}$ & $\underbrace{0}_{-1}$ & $\left.\left.\right|_{-1} ^{20}\right|_{-1} ^{20}$ & $\left.\left.\left.\left.\right|_{-1} ^{\infty}\right|_{-1} ^{\infty}\right|_{-1} ^{\infty}\right|_{-1} ^{\infty}$ & 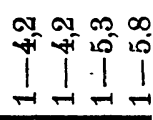 \\
\hline & 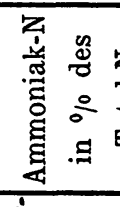 & & $\because 0$ & $1 \stackrel{0}{-}$ & $1 \stackrel{+H}{-\infty}$ & $\stackrel{\infty}{\rightarrow}|\stackrel{\infty}{\infty}| 1|1|$ & $\stackrel{\infty}{\infty} \mid 1 \stackrel{0}{n}$ \\
\hline 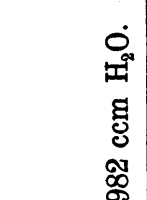 & 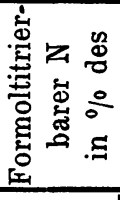 & & m & $\vec{\infty}=$ & 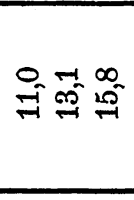 & 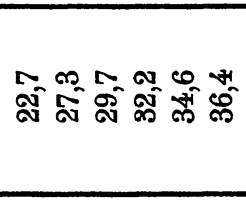 & 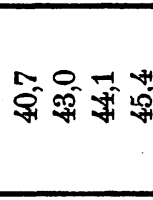 \\
\hline+ & 泀 & $\infty$ & $\underset{0}{\stackrel{2}{0}} \frac{\pi}{0}$ & $\underset{0}{\dddot{2}} \stackrel{\frac{9}{0}}{-1}$ & 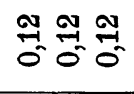 & 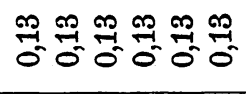 & 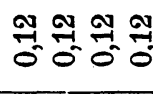 \\
\hline 离 & 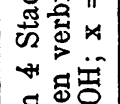 & $+i \mid$ & 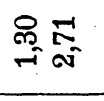 & 象 & $\begin{array}{l}8 \\
8\end{array}$ & 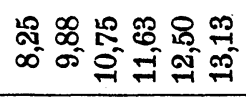 & 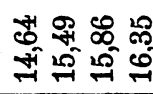 \\
\hline 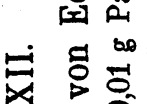 & 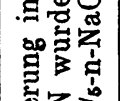 & $\infty$ & 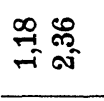 & 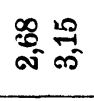 & 永采 & 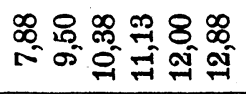 & 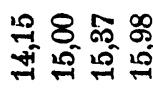 \\
\hline$\stackrel{\infty}{\Rightarrow} \stackrel{0}{\Xi}+$ & 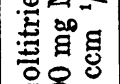 & oi & 造觜 & 绐 疍 & 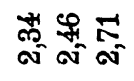 & 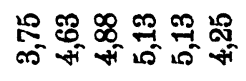 & 8 蛋 \\
\hline 究总密 & 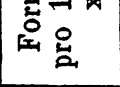 & $-i \mid$ & $\stackrel{\substack{0 \\
0}}{\stackrel{10}{=}}$ & $\stackrel{m_{1}}{=} \vec{m}$ & $\stackrel{8}{\rightarrow} \stackrel{\infty}{\infty}$ & 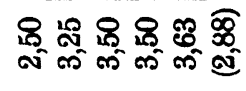 & 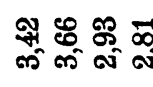 \\
\hline 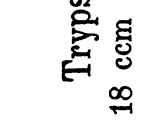 & 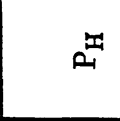 & & & & & & \\
\hline 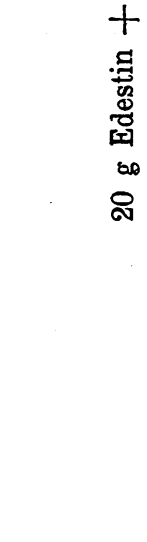 & & & 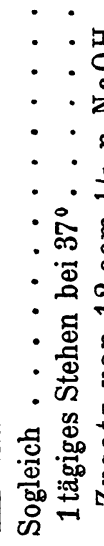 & 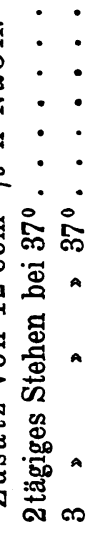 & 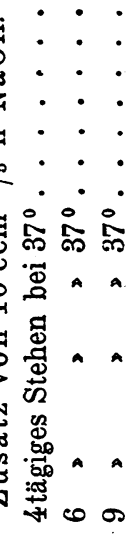 & 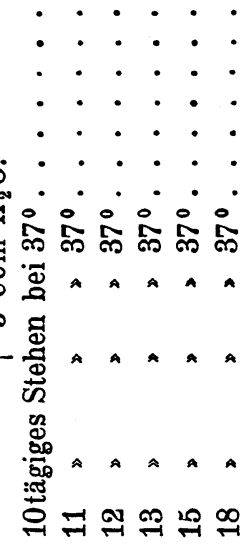 & 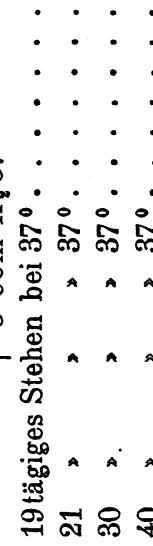 \\
\hline
\end{tabular}

Hoppe-Seyler's Zeitschrift f. physiol. Chemie. LXXV. 


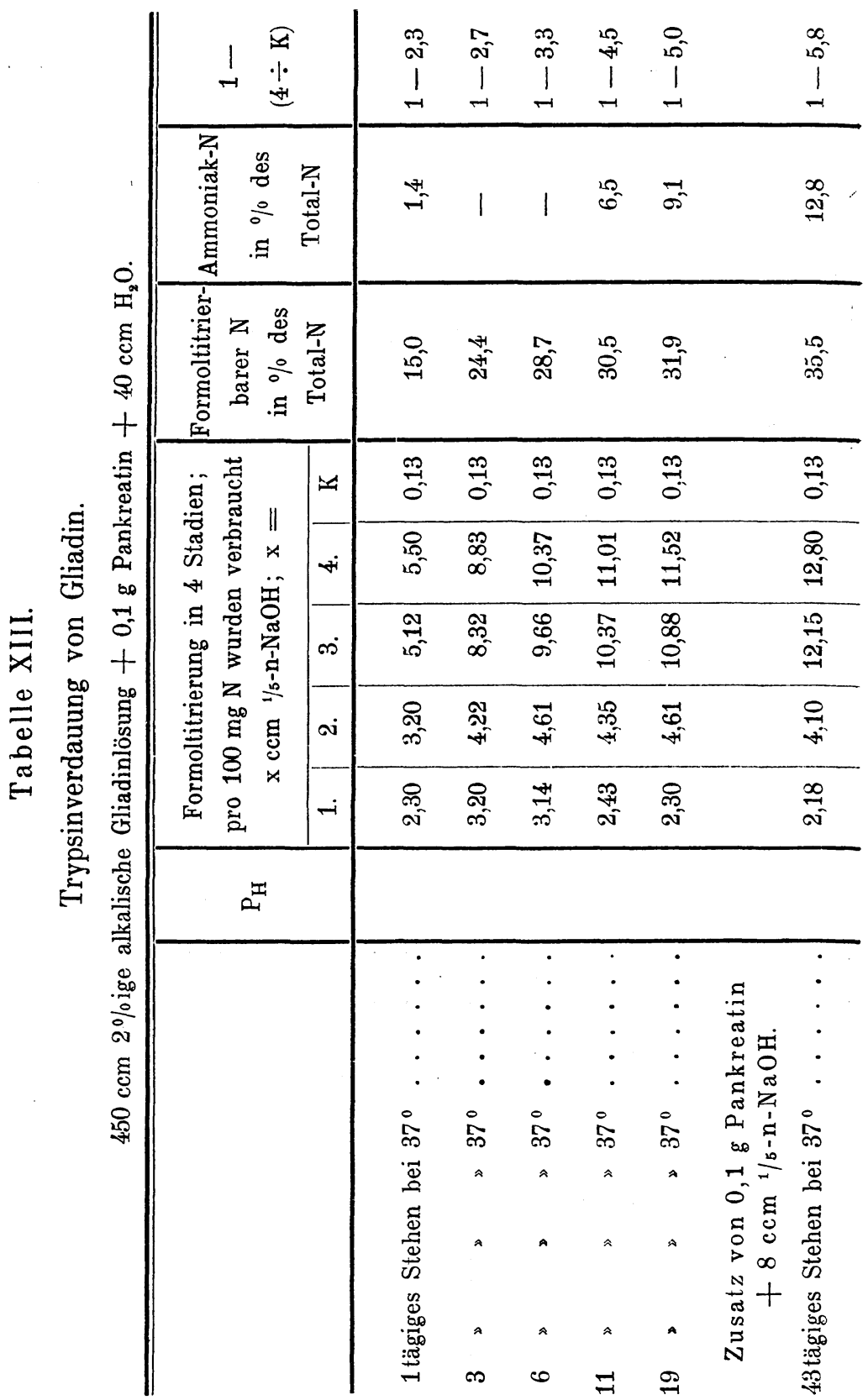


Über hydrolytische Spaltungen von Proteinen.

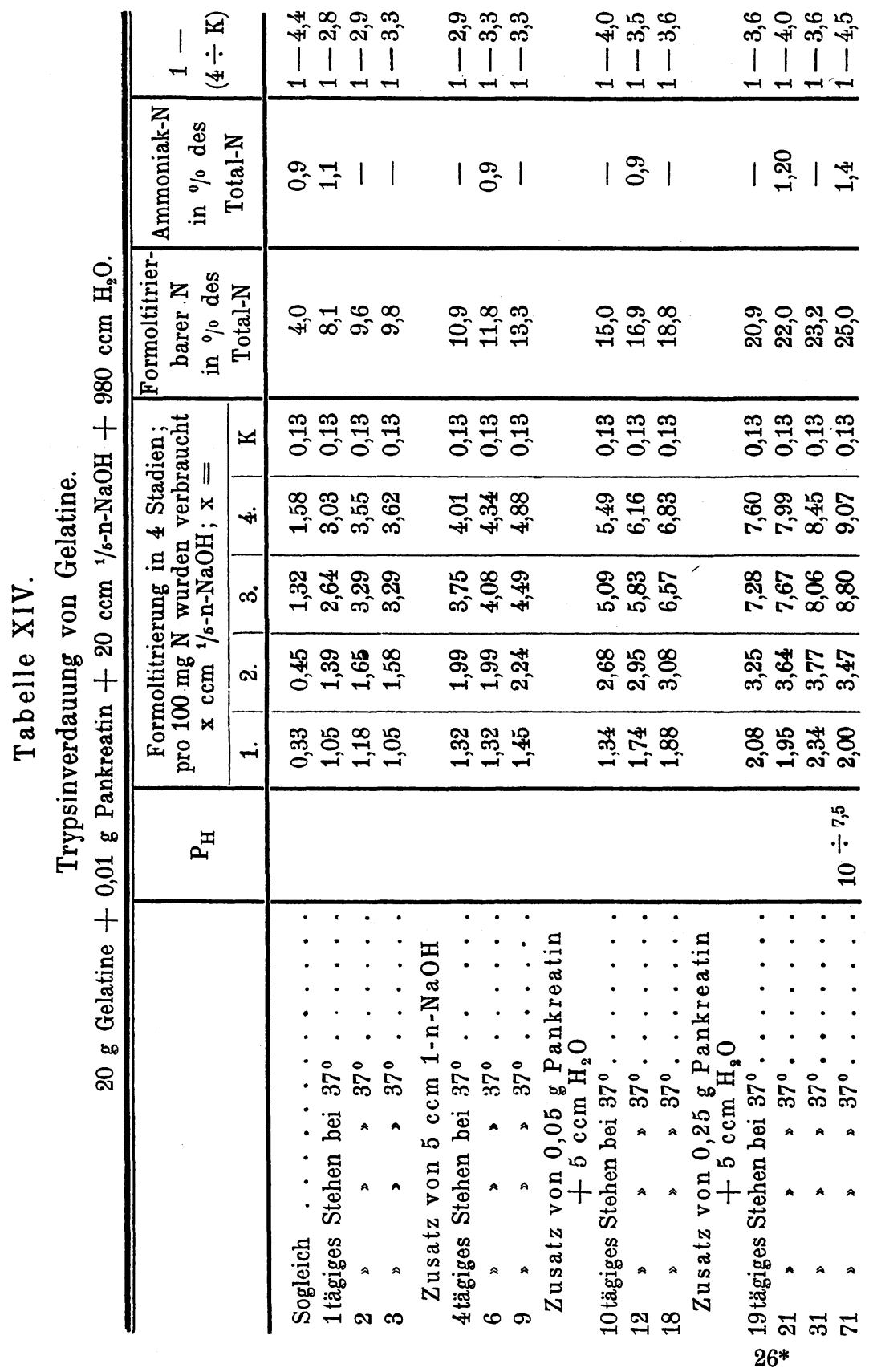


V. Henriques und J. K. Gjaldbæk,

\begin{tabular}{|c|c|c|c|c|c|c|}
\hline & $\begin{array}{c}1 \\
1 \\
-1\end{array}$ & & 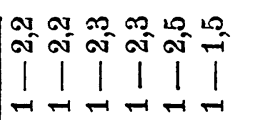 & $\begin{array}{lll}0 & 0 & 0 \\
0 & 0 & 0 \\
1 & 1 & 1 \\
-1 & -1\end{array}$ & 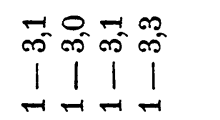 & 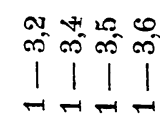 \\
\hline & 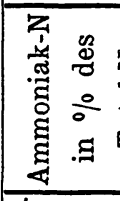 & & $\approx 1 \stackrel{\infty}{-} 11 \stackrel{0}{\circ}$ & $|\stackrel{0}{0}|$ & || ô 1 & $\stackrel{m}{\infty}|1|$ \\
\hline$\dot{0}$ & 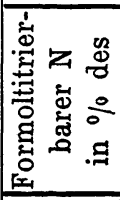 & & 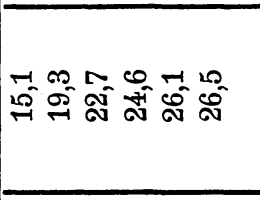 & 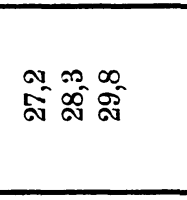 & 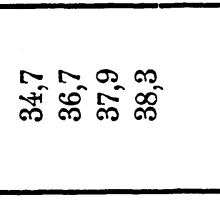 & 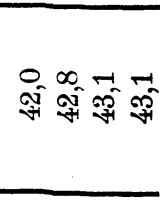 \\
\hline ذี & . & 4 & 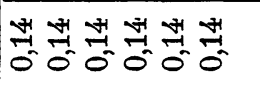 & 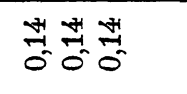 & 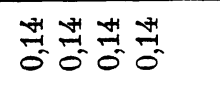 & 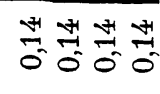 \\
\hline 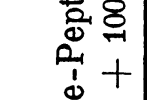 & 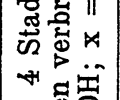 & نi & 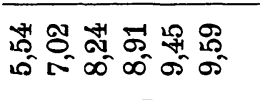 & 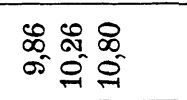 & 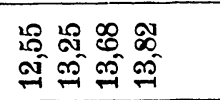 & 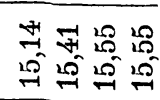 \\
\hline 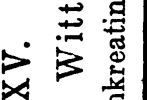 & 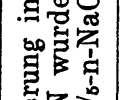 & $\dot{m}$ & 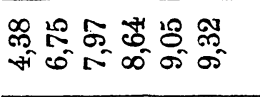 & 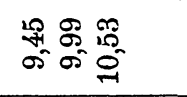 & 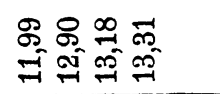 & 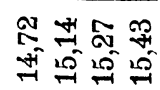 \\
\hline 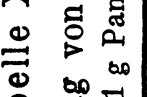 & 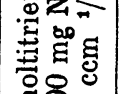 & oi & 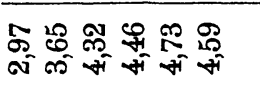 & 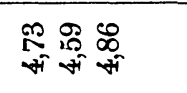 & 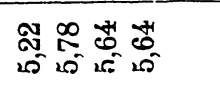 & 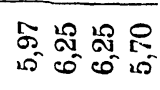 \\
\hline 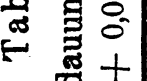 & 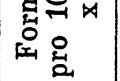 & $-i$ & 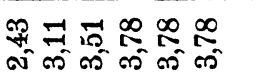 & $\underset{\infty}{\infty} \frac{\infty}{\infty}=\frac{\infty}{\infty}$ & 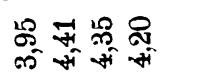 & 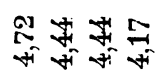 \\
\hline 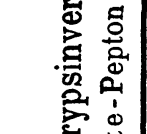 & ت & & & & & $\begin{array}{l}10 \\
0 \\
0 \\
0\end{array}$ \\
\hline 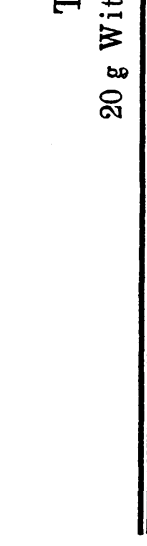 & & & 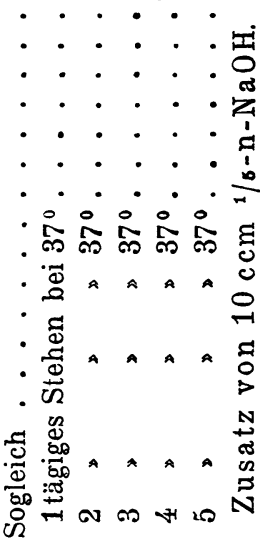 & 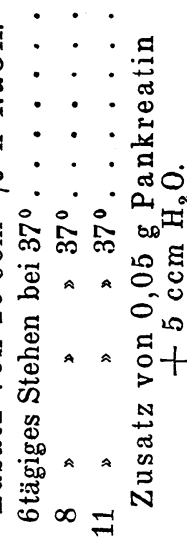 & 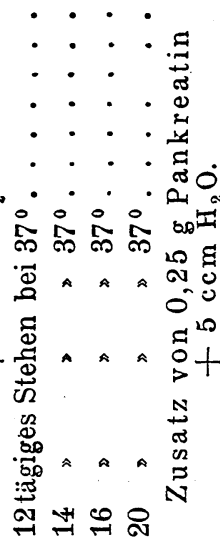 & 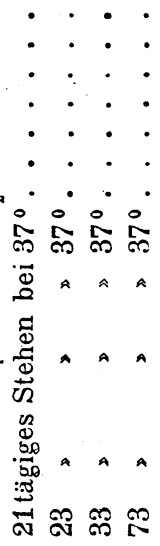 \\
\hline
\end{tabular}


Eine Vergleichung der Zahlen obenstehender Übersicht ${ }^{1}$ ) bestätigt das wohlbekannte Verhalten, daß die Trypsinverdauung eine stärkere Spaltung der Proteine bewirkt als die Pepsinverdauung. Jedoch ist der Unterschied, wenn man vom Hühnereiweiß absieht, nicht besonders groß, und bei der Gelatine und dem Gliadin ist sozusagen kein Unterschied zu verspüren. Bei dem Hühnereiweiß ist, wie man sieht, die Trypsinspaltung ungefähr doppelt so groß wie die Pepsinspaltung. Ferner sieht man, daß Hühnereiweiß das Protein ist, das von den untersuchten Proteinen bei der Trypsinverdauung am tiefsten gespalten wird. Daß Hühnereiweiß so stark gespalten wird, ist $u$. a. deswegen sonderbar, weil während des ganzen Versuchs nicht extra Trypsin zugesetzt wurde, was dagegen bei den übrigen Proteinen geschah. Die Fermentmenge im Versuche mit Hühnereiweiß betrug $1,25 \%$ des angewendeten Proteins, und das zu Anfang des Versuchs zugesetzte Trypsin hat also 73 Tage gewirkt.

Hühnereiweiß wird, wie erwähnt, stärker gespalten als sowohl Casein wie Witte-Pepton, was um so sonderbarer ist, als wir früher gefunden haben, ${ }^{2}$ ) daß Hühnereiweiß bei 12 stündigem Kochen mit 20\% iger Salzsäure keine vollständige Spaltung erfährt, während sowohl Casein als Witte-Pepton bereits nach 6 stündigem Kochen mit derselben Säure vollständig gespalten ist.

Vergleichen wir in der obigen Übersichtstabelle die Zahlen des formoltitrierbaren Stickstoffs nach Trypsinverdauung mit den entsprechenden Zahlen nach Totalspaltung im Autoklaven mit Säure, so wird man sehen, daß das Trypsin die Proteine nicht, einzelne (z. B. Gelatine) sogar bei weitem nicht vollständig $z u$ hydrolysieren vermag.

Die Formoltitrierung in Stadien, die bei allen Ver-

1) Bei später angestellten Versuchen erzielten wir sowohl bei Pepsinverdauung als bei Trypsinverdauung eine ein wenig stärkere Spaltung; wir führen an: pepsinverdautes Hühnereiweiß $38,0 \%$; pepsinverdautes Casein 38,5\% ; trypsinverdautes Hühnereiweiß 68,4\% ; trypsinverdautes Casein $60,0 \%$; trypsinverdautes Witte-Pepton $52,6 \%$; trypsinverdautes Fleisch 66,8\%.

2) V. Henriques und J. K. Gjaldbæk, Diese Zeitschrift, Bd. 67. 
suchen mit Trypsinverdauung unternommen worden ist, liefert uns, wie oben erwähnt, wichtige Aufschlüsse über die Art des Abbaus und zeigt uns, daß dieser bei der Trypsinverdauung von dem bei der Pepsinverdauung stattfindenden ganz verschieden ist. Der Unterschied zwischen den Wirkungsweisen der beiden Fermente tritt deutlich hervor, wenn wir das Verhältnis betrachten, das sich in den Tabellen in den Kolonnen findet, die mit $1-(4 \div \mathrm{K})$ bezeichnet sind; diese Größe gibt, wie öfters erwähnt, das Verhältnis an zwischen dem 1. und letzten (4.) Stadium $\div$ Kontrollösung bei der Titrierung. Während wir dieses Verhältnis sich bei der Pepsinverdauung zwar etwas, jedoch nicht viel ändern sahen, allmählich wie die Verdauung fortschritt, gewahren wir bei der Trypsinverdauung eine weit größere Abänderung des Verhältnisses, allmählich wie die Hydrolyse fortschreitet. Auch hier scheint wiederum das Hühnereiweiß eine Sonderstellung einzunehmen, indem wir bei diesem Protein die größte Abänderung antreffen.

Um die Wirkung des Pepsins leichter mit der des Trypsins vergleichen zu können, bringen wir unten einen Auszug der angeführten Versuchsergebnisse. Selbstredend muß man zu einer derartigen Vergleichung die Zahlen bezw. der Pepsinversuche und der Trypsinversuche dort aussuchen, wo die Zahlen des formoltitrierbaren Stickstoffs annäherungsweise möglichst gleich sind.

\begin{tabular}{c|c|c|c|c|c|c}
\hline \hline & $\begin{array}{c}\text { Formol- } \\
\text { titrier- } \\
\text { barer N }\end{array}$ & $\begin{array}{c}1- \\
(4 \div \mathrm{K})\end{array}$ & $\begin{array}{r}\text { Formol- } \\
\text { titrier- } \\
\text { barer N }\end{array}$ & $\begin{array}{c}1- \\
(4 \div \mathrm{K})\end{array}$ & $\begin{array}{r}\text { Formol- } \\
\text { titrier- } \\
\text { barer N }\end{array}$ & $\begin{array}{c}1- \\
(4 \div \mathrm{K})\end{array}$ \\
\hline $\begin{array}{c}\text { Pepsinverdautes } \\
\text { Hühnereiweiß }\end{array}$ & 14,9 & $1-2,2$ & 24,8 & $1-2,2$ & 31,9 & $1-2,3$ \\
$\begin{array}{c}\text { Trypsinverdautes } \\
\text { Hühnereiweiß }\end{array}$ & 14,5 & $1-5,5$ & 24,9 & $1-5,7$ & 30,1 & $1-6,1$ \\
\hline $\begin{array}{c}\text { Pepsinverdautes } \\
\text { Casein }\end{array}$ & 22,8 & $1-2,4$ & 28,4 & $1-2,6$ & 37,2 & $1-2,9$ \\
$\begin{array}{c}\text { Trypsinverdautes } \\
\text { Casein }\end{array}$ & 22,8 & $1-2,5$ & 28,3 & $1-2,8$ & 36,6 & $1-3,6$ \\
\hline $\begin{array}{c}\text { Pepsinverdautes } \\
\text { Edestin }\end{array}$ & 13,5 & $1-1,9$ & 23,1 & $1-2,1$ & 34,2 & $1-2,7$ \\
$\begin{array}{c}\text { Trypsinverdautes } \\
\text { Edestin }\end{array}$ & 13,1 & $1-2,5$ & 22,7 & $1-3,2$ & 34,6 & $1-3,4$ \\
\end{tabular}




\begin{tabular}{l|c|c|r|r|r|r}
\hline \hline & $\begin{array}{r}\text { Formol- } \\
\text { titrier- } \\
\text { barer N }\end{array}$ & $\begin{array}{c}1- \\
(4 \div \mathrm{K})\end{array}$ & $\begin{array}{r}\text { Formol- } \\
\text { titrier- } \\
\text { barer N }\end{array}$ & $\begin{array}{r}1- \\
(4 \div \mathrm{K})\end{array}$ & $\begin{array}{r}\text { Formol- } \\
\text { titrier- } \\
\text { barer N }\end{array}$ & $\begin{array}{c}1-1 \\
(4 \div \mathrm{K})\end{array}$ \\
\hline $\begin{array}{c}\text { Pepsinverdautes } \\
\text { Gliadin }\end{array}$ & - & - & 29,9 & $1-4,2$ & 33,3 & $1-4,1$ \\
$\begin{array}{c}\text { Trypsinverdautes } \\
\text { Gliadin }\end{array}$ & - & - & 30,5 & $1-4,5$ & 35,5 & $1-5,8$ \\
\hline $\begin{array}{c}\text { Pepsinverdaute } \\
\text { Gelatine }\end{array}$ & 18,9 & $1-2,7$ & 22,9 & $1-3,1$ & 23,8 & $1-3,2$ \\
$\begin{array}{c}\text { Trypsinverdaute } \\
\text { Gelatine }\end{array}$ & 18,9 & $1-3,6$ & 23,2 & $1-3,6$ & 25,0 & $1-4,5$ \\
\hline $\begin{array}{c}\text { Pepsinverdautes } \\
\text { Witte-Pepton }\end{array}$ & - & - & - & - & 36,7 & $1-2,6$ \\
$\begin{array}{c}\text { Trypsinverdautes } \\
\text { Witte-Pepton }\end{array}$ & - & - & - & - & 36,7 & $1-3,0$ \\
\end{tabular}

Aus den hier ausgezogenen Zahlen wird man sehen, daß das Verhältnis $1-(4 \div \mathrm{K})$ verschieden ist, je nachdem wir mit einer Pepsin- oder einer Trypsinverdauung zu tun haben, wenn auch die Menge formoltitrierbaren Stickstoffs die gleiche ist. Wir sehen, daß der Unterschied überall dadurch hervortritt, daß das 1. Stadium bei der Pepsinverdauung größer ist als das 1. Stadium bei der Trypsinverdauung (das Verhältnis $1-(4 \div \mathrm{K})$ ist in ersterem Falle enger als in letzterem). Der Unterschied ist indessen nicht derselbe bei allen untersuchten Proteinen; beim Witte-Pepton ist er verhältnismäßig gering, beim Hühnereiweiß hingegen sehr groß. Inwiefern dieser Unterschied zwischen einem peptischen und tryptischen Spaltungsprodukt etwas mit dem Vorhandensein des Ammoniaks zu tun hat, haben wir untersucht, indem wir nach Entfernung des Ammoniaks durch Abdestillation im Vakuum Formoltitrierungen in Stadien unternahmen; die Entfernung von Ammoniak ergab indessen keine wahrnehmbare Abänderung des Verhältnisses $1-(4 \div \mathrm{K})$. Es bestand auch an und für sich kein Grund anzunehmen, daß ein Vorhandensein von Ammoniak imstande sei, den angetroffenen sonderbaren Unterschied des Verhältnisses $1-(4 \div \mathrm{K})$ bei der Pepsinverdauung und der Trypsinverdauung zu erzeugen; denn bei der Pepsinverdauung ist die 
Ammoniakmenge größer, aber Ammoniak wird bei Formoltitrierung in Stadien ein sehr kleines 1. Stadium aufweisen, also ein weites Verhältnis zwischen dem 1. und 4. Stadium, und gerade das Umgekehrte finden wir bei der Pepsinverdauung.

Aus dem hier Angeführten dürfte man berechtigt sein zu schließen, daß die Art der Spaltung verschieden ist, je nachdem wir Pepsin oder Trypsin anwenden, wenn auch der Grad der Spaltung derselbe ist; wir dürfen ferner aus den gefundenen Zahlen (namentlich des Verhältnisses $1-(4 \div \mathrm{K})$ ) schließen, daß das Pepsin eine große Menge Peptide und sehr wenig freie Aminosäuren bildet, während das Trypsin außer Peptiden eine verhältnismäßig große Menge freier Aminosäuren abspaltet - auch von Anfang der Verdauung an - groß genug, um eine bedeutende Verschiebung des Verhältnisses $1-(4 \div \mathrm{K})$ zu erzeugen.

Betrachten wir das Verhältnis $1-(4 \div \mathrm{K})$ zu Ende der Versuche mit Trypsin, so sehen wir aus der Größe dieses Verhältnisses, daß in den Verdauungsflüssigkeiten eine sehr große Menge freier Aminosäuren vorhanden sein muß. Hier ist wiederum die Abänderung am größten beim Hühnereiweiß, indem wir zuletzt ein Verhältnis $=1-10,5$ haben. Edestin und Gliadin weisen ein Verhältnis $=1-5,8$ auf, obgleich die Spaltung nicht besonders intensiv ist (formoltitrierbarer $\mathrm{N}$ bezw. 45,4 und 35,5). Danach kommt Gelatine mit 1-4,5 (formoltitrierbarer $\mathrm{N}$ nur $25 \%$ ), Casein mit 1-4,0 (formoltitrierbarer $N 42,5 \%$ ) und schließlich Witte-Pepton mit 1-3,6 (formoltitrierbarer $\mathrm{N}$ 43,1\%). Der Grund dazu, daß das Verhältnis $1-(4 \div \mathrm{K})$ beim Witte-Pepton nicht weiter gelangte, ist - wie wir unten näher besprechen werden - in dem Umstand zu suchen, daß dieser Stoff durch eine Pepsinverdauung hergestellt ist.

Die Ammoniakabspaltung der Trypsinverdauung ergibt sich als höchst verschieden bei den verschiedenen Proteinen. Dies geht deutlich aus untenstehender Übersicht hervor, in der die zu Ende der Versuche gefundenen Zahlen der Ammoniakmenge (in Prozent des Totalstickstoffs) angeführt sind; vergleichshalber haben wir auch die Ammoniakmenge angeführt, die sich bei vollständigem Abbau der untersuchten Proteine 
bei $1^{1 / 2}$ stündiger Erwärmung im Autoklaven auf $150^{\circ} \mathrm{mit}$ 3 n-HCl bildet. ${ }^{1}$ )

\begin{tabular}{l|c|c}
\hline & $\begin{array}{c}\text { Ammoniak } \\
\text { bei der Trypsinverdauung } \\
\%\end{array}$ & $\begin{array}{c}\text { Ammoniak } \\
\text { bei totaler Spaltung } \\
\%\end{array}$ \\
\hline Hühnereiweiß.... & 4,6 & 9,5 \\
Casein . . . . . . & 5,1 & 11,9 \\
Edestin....... & 7,0 & 14,0 \\
Gliadin . . . . . & 12,8 & 24,8 \\
Gelatine . . . . . & 1,4 & 3,7 \\
Witte-Pepton.... & 3,3 & 8,9
\end{tabular}

Die stärkste Ammoniakbildung finden wir - wie bei der Pepsinwirkung - beim Gliadin, während wir aber bei den Pepsinversuchen eine 20,9\% des Totalstickstoffes entsprechende Ammoniakmenge fanden, finden wir hier nur 12,8\%. Bei der Pepsinverdauung näherte die abgespaltene Ammoniakmenge sich stark derjenigen, die man bei totaler Spaltung erhält (nämlich 24,8); bei der Trypsinverdauung wird dagegen nur zirka die Hälfte der Ammoniakmenge abgespalten, die sich bei der totalen Spaltung abspaltet.

Am wenigsten Ammoniak wird von der Gelatine gebildet $(1,4 \%)$, während die Menge bei den übrigen Proteinen zwischen $3,3 \%$ und $7,0 \%$ schwankt. Um die Ammoniakabspaltung bei der Trypsinverdauung richtig mit der bei der Pepsinverdauung stattfindenden vergleichen zu können, muß man zum Vergleiche solche Versuche wählen, wo die Menge des formoltitrierbaren Stickstoffs in beiden Fällen so weit möglich die gleiche ist. Eine solche Auslese ist in untenstehender Zusammenstellung geschehen.

Aus den hier angeführten Zahlen geht sehr deutlich hervor, daß die Ammoniakabspaltung bei der Pepsineinwirkung viel intensiver ist, als bei der Trypsineinwirkung, was das von uns durch Formoltitrierung in Stadien gewonnene Resultat, daß die Wirkungsweise des Pepsins in hohem Grade von der des Trypsins abweicht, noch bestätigt.

1) V. Henriques und J. K. Gjaldbæk, Diese Zeitschrift, Bd. 67. 


\begin{tabular}{|c|c|c|c|c|}
\hline & $\begin{array}{c}\text { Formol- } \\
\text { titrier- } \\
\text { barer } \mathrm{N} \\
\text { in } \% \text { des } \\
\text { Total- } \mathrm{N}\end{array}$ & $\begin{array}{c}\text { Am- } \\
\text { moniak-N } \\
\text { in } \% \text { des } \\
\text { Total-N }\end{array}$ & $\begin{array}{c}\text { Formol- } \\
\text { titrier- } \\
\text { barer } \mathrm{N} \\
\text { in } \% \mathrm{des} \\
\text { Total-N }\end{array}$ & $\begin{array}{c}\text { Am- } \\
\text { moniat-N } \\
\text { in } \% \text { des } \\
\text { Total-N }\end{array}$ \\
\hline Pepsinverdautes Hühnereiweiß & 14,9 & 1,9 & 24,8 & $4, \tilde{5}$ \\
\hline Trypsinverdautes & 14,5 & 1,0 & 24,9 & 1,4 \\
\hline Pepsinverdautes Casein . . & 21,0 & 3,3 & 26,8 & 6,2 \\
\hline Trypsinverdautes $\gg . .$. & 21,2 & 1,4 & 26,6 & 1,7 \\
\hline Pepsinverdautes Edestin . . & 15,9 & 4,0 & 23,4 & 7,2 \\
\hline Trypsinverdautes & 15,8 & 1,4 & 22,7 & 1,8 \\
\hline Pepsinverdautes Gliadin . . & - & 一 & 29,9 & 18,3 \\
\hline Trypsinverdautes » .. & - & - & 30,5 & 6,5 \\
\hline Pepsinverdautes Witte-Pepton & 28,8 & $\underline{5,2}$ & 36,7 & 6,0 \\
\hline Trypsinverdautes & 28,3 & 2,0 & 37,9 & 2,4 \\
\hline
\end{tabular}

Der erwähnte Unterschied der Ammoniakabspaltung tritt übrigens sehr früh in der Verdauung hervor, beim Casein und Edestin bereits nach 3 Tagen; ja der Unterschied ist im ganzen genommen völlig so stark ausgeprägt, wenn die Verdauung nicht so weit fortgeschritten ist.

\section{Versuche mit Pepsinverdauung von Proteinen, die zuvor einer Trypsin- verdauung unterworfen waren.}

Oben wurde erwähnt, daß man bei der Bestimmung des Abbaugrades eines Proteinstoffes durch Formoltitrierung in Stadien zugleich Aufschluß erhält über die Art der Spaltung, und daß man imstande war, aus diesem Verhältnis in Verbindung mit einer Bestimmung der Ammoniakabspaltung nachzuweisen, daß ein Protein in verschiedener Weise verdaut wird, je nachdem es einer Pepsinverdauung oder einer Trypsinverdauung unterworfen wird. Dies heißt mit anderen Worten, daß der formoltitrierbare Stickstoff, wenn man einen bestimmten Spaltungsgrad erreicht hat, nicht in derselben Weise in eìnem peptischen Spaltungsprodukt vorhanden ist, wie in einem tryptischen. Wie erwähnt, konnte man durch lange dauernde Pepsinverdauung die Proteine so stark spalten, daß 30-40\% des Stickstoffs formoltitriert werden konnten. Es würde danach 
von Interesse sein, zu sehen, wie sich ein tryptisches Spaltungsprodukt eines Spaltungsgrades von 30-40\% formoltitrierbaren Stickstoffs Pepsin-Salzsäure gegenüber verhalten würde, indem ein solches Spaltungsprodukt voraussichtlich Bindungen enthalten müßte, die das Pepsin zu lösen imstande wäre. Wir geben unten in Tabelle XVI das Resultat der Versuche wieder, die wir in dieser Beziehung angestellt haben.

Die Zahlen der Tabelle XVI zeigen, daß in allen Versuchen durch die Pepsin-HCl-Einwirkung eine weitere Spaltung geschehen ist; wir stellen übersichtshalber die stattgefundene Veränderung tabellarisch zusammen.

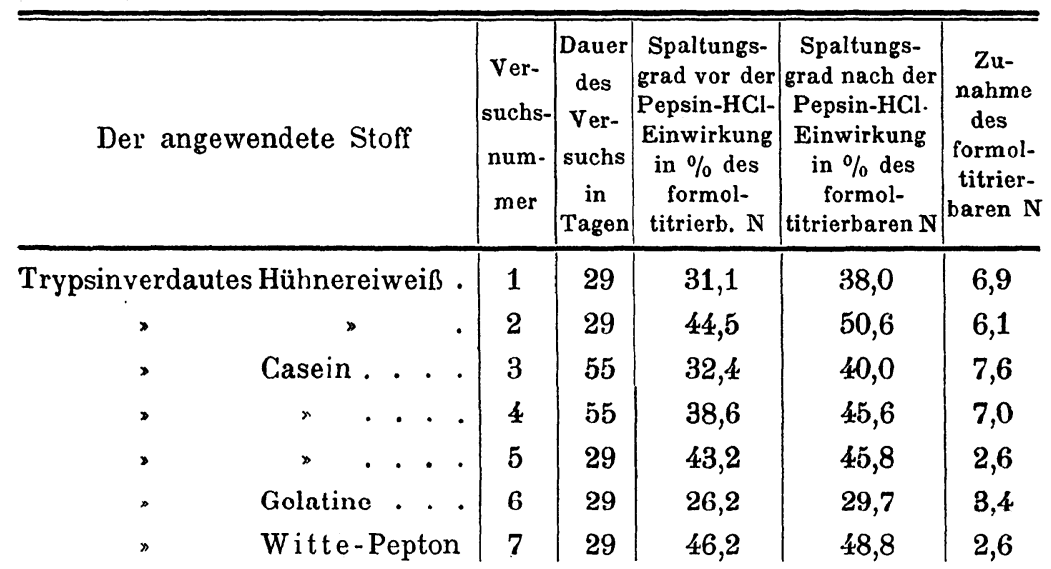

Wie man sieht, betrug die Vermehrung des formoltitrierbaren Stickstoffs von 2,6 bis 7,6\% der Totalstickstoffmenge. Betrachtet man dagegen in der Haupttabelle die Weise, in der die Vermehrung stattfand, so sieht man, daß die Spaltung in Versuch 1 namentlich am ersten Tage stattgefunden hat und danach sehr langsam verlief; die Spaltung scheint somit hier zweifelsohne eine Pepsinwirkung zu sein. In den übrigen Versuchen geschieht dagegen die Vermehrung des formoltitrierbaren Stickstoffs langsam und regelmäßig zunehmend, und inwiefern die stattgefundene Veränderung hier einer Pepsinwirkung oder ausschließlich einer Säurewirkung zuzuschreiben ist, läßt sich aus den Versuchsresultaten nicht entscheiden; man muß, um Einsicht darüber zu gewinnen, Kontrollversuche anstellen mit 


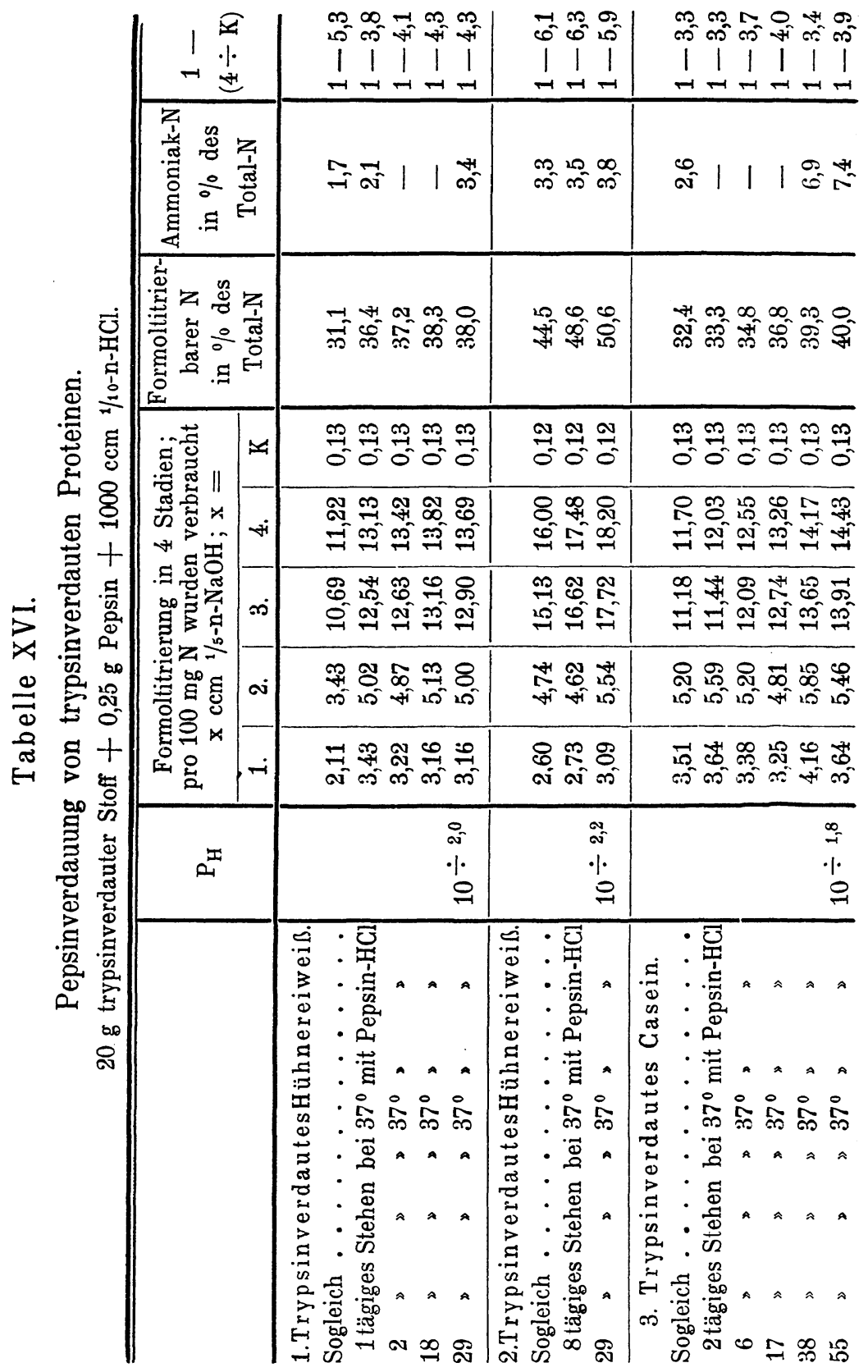


Über hydrolytische Spaltungen von Proteinen.

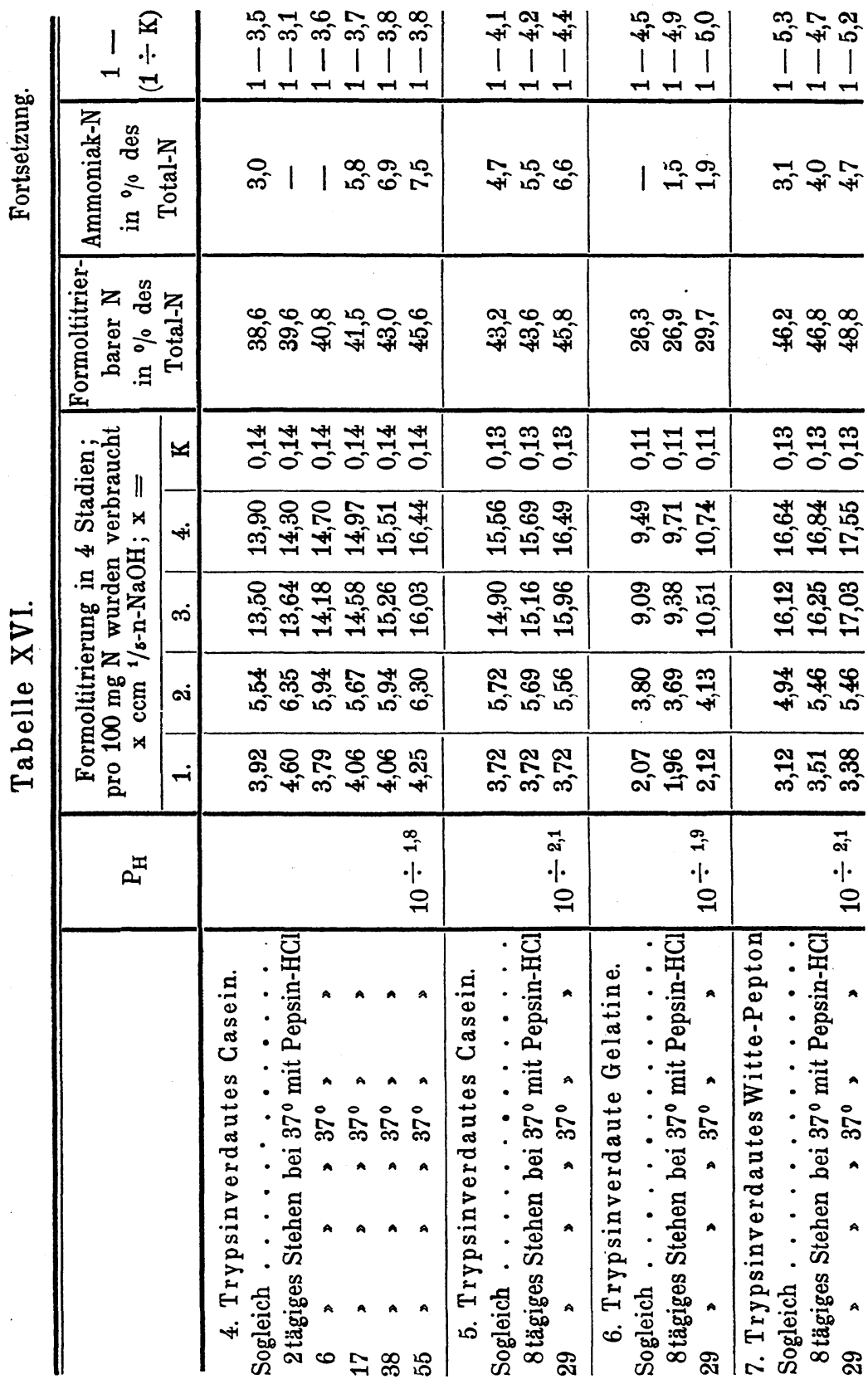


inaktiviertem Pepsin, und das Verhältnis bedarf somit einer näheren Untersuchung. Halten wir uns indessen an Versuch 1, so liefert derselbe eine weitere Bestätigung des früher erwähnten Verhältnisses, daß die Pepsin- und die Trypsinverdauung verschieden sind. Ein peptisches Spaltungsprodukt eines Spaltungsgrades von $31 \%$ formoltitrierbaren Stickstoffs würde sich nämlich bei Pepsin-Salzsäureeinwirkung im Laufe eines Tages nicht annähernd so stark spalten (siehe in Tabelle II die Geschwindigkeit der Spaltung nach Zusatz von frischem Pepsin).

Die bei den Versuchen der Tabelle XVI angewendete Pepsinmenge betrug $0,5 \mathrm{~g}$ per Liter Flüssigkeit, war also eine so geringe, daß die infolge der Selbstverdauung des Pepsins stattfindende Vermehrung des formoltitrierbaren Stickstoffs durchaus keine Rolle spielt.

Das Verhältnis $1-(4 \div \mathrm{K})$ : Dies Verhältnis weist in den meisten Versuchen keine wesentliche Veränderung auf; im ersten Versuche ändert es sich jedoch im Laufe des ersten Tages von $1-5,3$ in $1-3,8$. Das Verhältnis wurde hier also enger, was eine typische Pepsinwirkung erweist. Die Veränderung läßt sich erklären, wenn wir, wie früher erwähnt, annehmen, daß das Trypsin in der Weise wirkt, daß es vom großen Proteinmolekül Aminosäuren abspaltet und ein großes Molekül übrig läßt, sodaß das Verhältnis $1-(4 \div \mathrm{K})$ der vorhandenen Aminosäuren wegen weit wird. Wird nun ein solches Spaltungsprodukt einer Pepsinverdauung unterworfen, so wird der Rest des großen Proteinmoleküls angegriffen und in Polypeptide gespalten; in diesen ist das Verhältnis $1-(4 \div \mathrm{K})$ sehr eng, und es wird imstande sein, die Veränderung zu bewirken, die der Versuch aufweist. Wenn von den Versuchen mit Hühnereiweiß abgesehen wird, so ist die Zunahme des formoltitrierbaren Stickstoffs nicht viel größer als die des Ammoniaks.

Die Menge des Ammoniaks nimmt in allen Versuchen zu; jedoch findet sich in den Versuchen mit Hühnereiweiß keine große Zunahme; am größten ist die Zunahme beim Casein.

Wird der Prozentsatz des Ammoniaks mit den entsprechenden Zahlen aus den Versuchen mit reiner Pepsinverdauung verglichen, wo der Spaltungsgrad derselbe war wie in den 
Versuchen der Tabelle XVI, so sieht man, daß die Ammoniakmenge in den Versuchen mit reiner Pepsinverdauung am größten ist. Vergleicht man indessen (für einen und denselben Proteinstoff) die Ammoniakzahlen nach der Zeit, wo der Stoff der Wirkung der Pepsin-Salzsäure ausgesetzt war, so entsprechen sie einander sehr genau.

\section{Versuche mit Trypsinverdauung peptischer Spaltungsprodukte.}

In den Tabellen XVII-XX geben wir das Resultat einiger Versuche über die Trypsinverdauung peptischer Spaltungsprodukte von Hühnereiweiß, Casein, Gelatine und Witte-Pepton wieder.

Diese Versuche zeigen bei einer Vergleichung mit früher angeführten Versuchen, was den Spaltungsgrad betrifft, daß eine Pepsin- + Trypsinverdauung eine stärkere Spaltung bewirkt als die Trypsinverdauung allein und ferner eine stärkere Spaltung als eine Trypsin- + Pepsinverdauung. Der höchste von uns erzielte Spaltungsgrad bei Pepsin- + Trypsinverdauung beträgt $62,8 \%$ formoltitrierbaren $\mathrm{N}$, und zwar bei Hühnereiweiß.

Die Formoltitrierung in Stadien zeigt uns sogleich die Trypsinwirkung, indem das Verhältnis $1-(4 \div \mathrm{K})$, allmählich wie die Verdauung fortschreitet, immer weiter wird. Jedoch gibt die vorhergegangene Pepsinverdauung, der der Stoff unterworfen war, sich deutlich zu erkennen, indem das Verhältnis $1-(4 \div \mathrm{K})$ auch nach langwieriger Trypsinwirkung und starker Spaltung nicht so weit wird, wie bei der rein tryptischen Verdauung; die Vergleichung muß wie gewöhnlich mit Spaltungsprodukten desselben Proteins und bei annäherungsweise gleich großem Gehalt an formoltitrierbarem Stickstoff angestellt werden. Wird eine solche Vergleichung angestellt, so wird man, was das Hühnereiweiß betrifft, einen sehr großen Unterschied zwischen einem rein tryptischen und einem peptisch + tryptischen Spaltungsprodukt des gleichen Spaltungsgrades antreffen; bei der Gelatine ist der Unterschied geringer, aber doch deutlich; beim Witte-Pepton und Casein dagegen liegt der geringe Unterschied, der wahrgenommen wird, innerhalb des Gebietes des Versuchs- 


\begin{tabular}{|c|c|c|c|c|c|c|}
\hline & $\begin{aligned} 0 \\
1 \\
1 \\
1 \\
0\end{aligned}$ & & 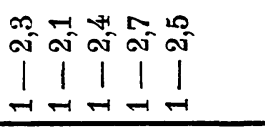 & $\begin{array}{ll}0 & 0 \\
0 & 0 \\
1 & 1\end{array}$ & 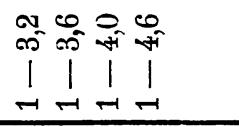 & 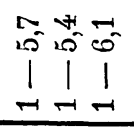 \\
\hline & 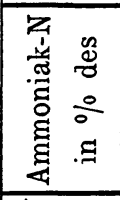 & & $\Rightarrow 10111$ & 201 & $111 \overrightarrow{20}$ & 1180 \\
\hline 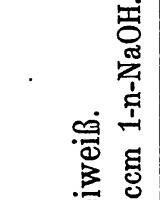 & 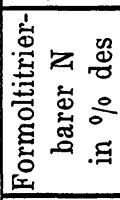 & & ผ0. & 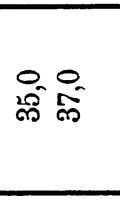 & 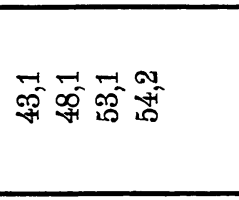 & $\begin{array}{l}0 \\
0 \\
0 \\
0 \\
0\end{array}$ \\
\hline 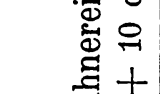 & . & 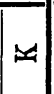 & 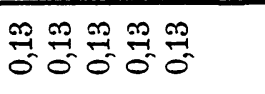 & $\begin{array}{l}m \\
\ddot{0} \\
0\end{array}$ & 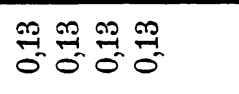 & 里 \\
\hline \& & 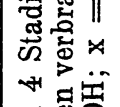 & *i & 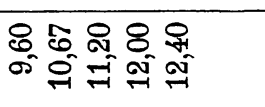 & 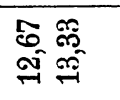 & 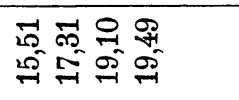 & 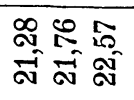 \\
\hline 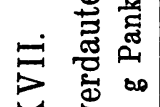 & 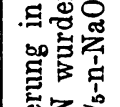 & $\infty$ & 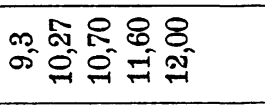 & 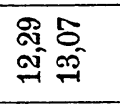 & 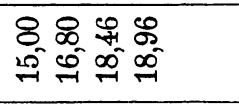 & 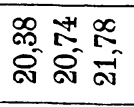 \\
\hline $\begin{array}{ll}4 & 0 \\
0 & 0 \\
0 & 0 \\
0 & 0 \\
0 & 0 \\
0 & +\end{array}$ & 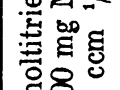 & oi & 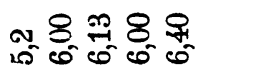 & $\begin{array}{l}-1 \\
0 \\
0 \\
0\end{array}$ & 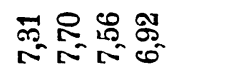 & 俞总茎 \\
\hline ह & | & $-i \mid$ & 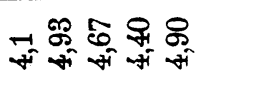 & 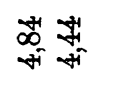 & से & 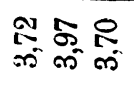 \\
\hline 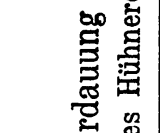 & 虍 & & & & & \begin{tabular}{l}
$\infty$ \\
\multirow{\infty}{\infty}{} \\
1 \\
0 \\
0
\end{tabular} \\
\hline 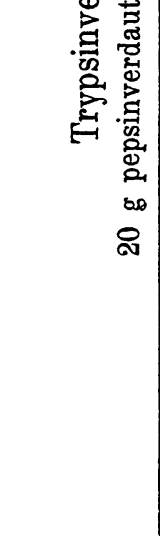 & & & 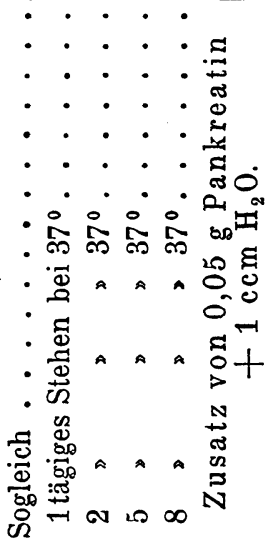 & 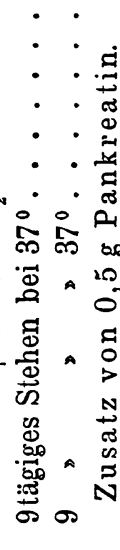 & 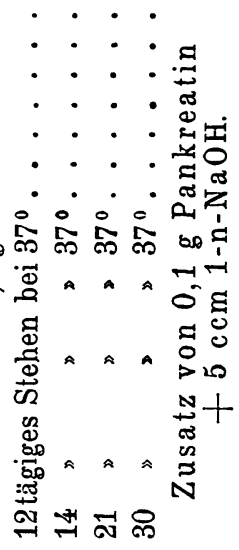 & 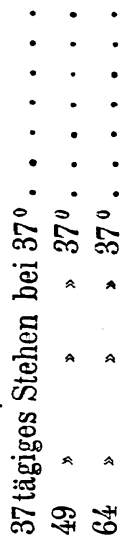 \\
\hline
\end{tabular}


Tabelle XVIII.

Trypsinverdauung von pepsinverdautem Casein.

$10 \mathrm{~g}$ pepsinverdautes Casein $+0,25 \mathrm{~g}$ Pankreatin $+500 \mathrm{ccm} \mathrm{H}_{2} \mathrm{O}+5 \mathrm{ccm} 1 \mathrm{n}-\mathrm{NaOH}$.

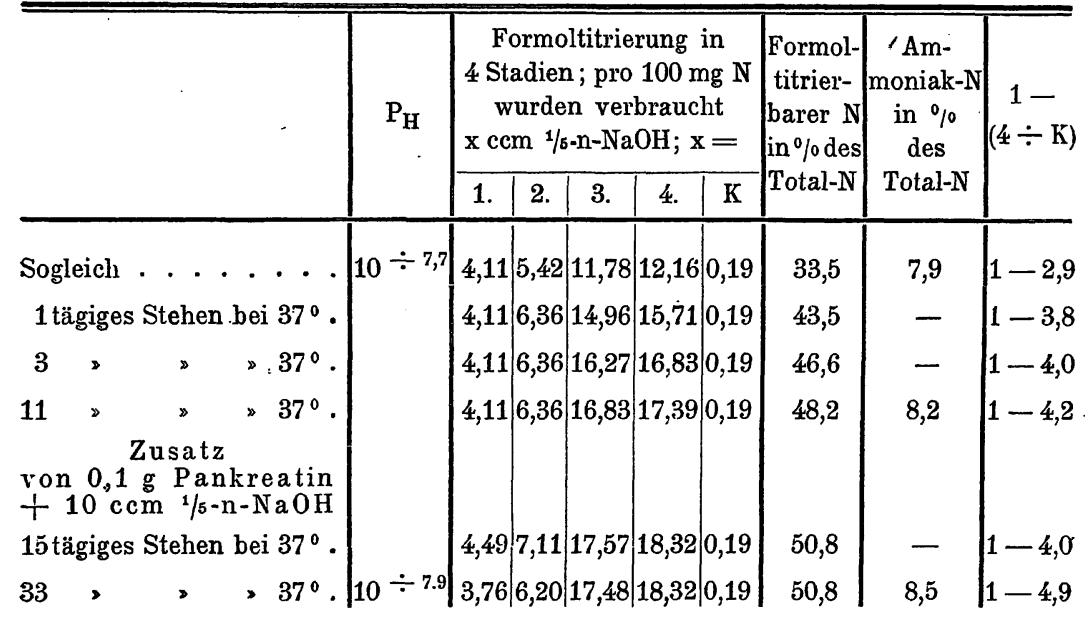

\section{Tabelle XIX.}

Trypsinverdauung von pepsinverdauter Gelatine.

$500 \mathrm{ccm} 20 \%$ ige alkalische Lösung von pepsinverdauter Gelatine $+0,25 \mathrm{~g}$ Pankreatin.

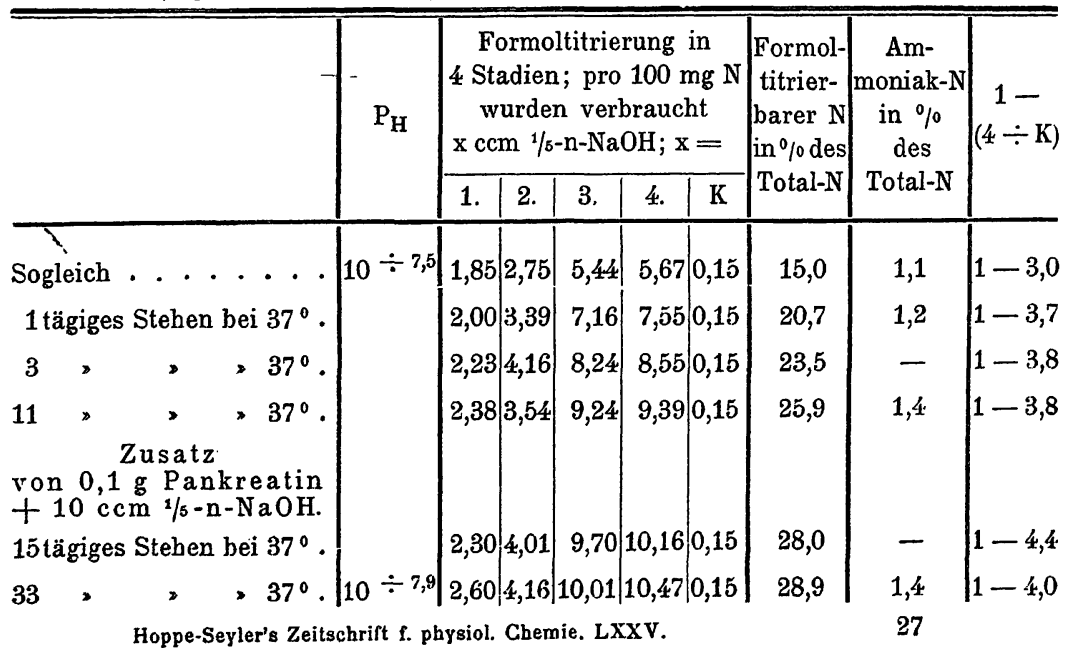




\section{Tabelle XX.}

Trypsinverdauung von pepsinverdautem Witte-Pepton. $500 \mathrm{ccm} 2 \%$ ige alkalische Lösung von pepsinverdautem Wit te-Pepton $+0,1 \mathrm{~g}$ Pankreatin.

\begin{tabular}{c}
\hline \\
\hline
\end{tabular}

fehlers. Beim Witte-Pepton ist dies jedoch leicht zu erklären, indem dieser Stoff selbst ein peptisches Spaltungsprodukt ist. Zur Aufklärung des erwähnten Unterschiedes zwischen rein tryptischen und peptisch + tryptischen Spaltungsprodukten von Hühnereiweiß und Gelatine extrahieren wir aus den Tabellen vergleichshalber folgende Zahlen:

\begin{tabular}{|c|c|c|c|c|c|c|}
\hline & $\begin{array}{l}\text { Spal- } \\
\text { tungs- } \\
\text { grad }\end{array}$ & $\begin{array}{c}1- \\
(4 \div \mathrm{K})\end{array}$ & $\begin{array}{c}\text { Spal- } \\
\text { tungs- } \\
\text { grad }\end{array}$ & $\begin{array}{c}1- \\
(4 \div \mathrm{K})\end{array}$ & $\begin{array}{c}\text { Spal- } \\
\text { tungs- } \\
\text { grad }\end{array}$ & $\begin{array}{c}1- \\
(4 \div \mathrm{K})\end{array}$ \\
\hline $\begin{array}{l}\text { Pepsin- + trypsin- } \\
\text { verdaute Gelatine }\end{array}$ & 25,9 & $1-3,8$ & - & - & - & - \\
\hline $\begin{array}{c}\text { Trypsinverdaute } \\
\text { Gelatine }\end{array}$ & 25,0 & $1-4,5$ & - & - & - & - \\
\hline $\begin{array}{l}\text { Pepsin-+ trypsinver- } \\
\text { dautes Hühnereiweiß }\end{array}$ & 35,0 & $1-3,0$ & 54,2 & $1-4,6$ & 60,6 & $1-5,4$ \\
\hline $\begin{array}{c}\text { Trypsinverdautes } \\
\text { Hühnereiweiß }\end{array}$ & 35,0 & $1-7,1$ & 53,9 & $1-9,3$ & 60,2 & $1-10,5$ \\
\hline
\end{tabular}

Der große, sich namentlich beim Hühnereiweiß geltend machende Prozentsatz läßt sich - in Übereinstimmung mit dem früher über die Pepsinverdauung und die Trypsinverdauung Angeführten - durch die Annahme erklären, daß der peptidgebundene Stickstoff in einem rein tryptischen Spaltungsprodukt 
in größeren Molekülen vorhanden ist, als in einem peptisch + tryptischen Spaltungsprodukt desselben Spaltungsgrades. Als Beispiel eines solchen Verhältnisses führen wir an, daß eine Mischung gleich vieler Moleküle Glycin und Diglycylglycin die gleiche Menge «peptidgebundenen * Stickstoffs enthält wie Glycylglycin. Was erstere Mischung betrifft, muß man indessen des vorhandenen Glycins wegen annehmen, daß das Verhältnis $1-(4 \div \mathrm{K})$ weiter ist als beim Glycylglycin.

Die Ammoniakmenge hält sich in diesen Versuchen lange Zeit konstant; erst nach längerer Einwirkung von Trypsin auf die pepsinverdauten Proteine wird noch ein wenig Ammoniak abgespalten.

\section{Spaltung mit Säuren und Alkalien.}

Zur Vergleichung mit der Pepsinverdauung und der Trypsinverdauung, die namentlich beim Hühnereiweiß viele eigentümliche Verhältnisse aufwiesen, haben wir einige Spaltungen dieses Proteinstoffs mit $\mathrm{HCl}, \mathrm{H}_{2} \mathrm{SO}_{4}$ und $\mathrm{NaOH}$ ausgeführt; das Resultat dieser Versuche ist in den Tabellen XXI--XXIII inkl. veranschaulicht.

Die Tabelle XXI enthält unter dem Titel «formoltitrierbarer N, die durch die betreffenden Säuren oder $\mathrm{NaOH}$ in schwächeren oder stärkeren Konzentrationen, bei verschiedenen Temperaturen und in verschiedenen Zeiträumen bewirkte Spaltung.

Die Ammoniakbildung ist, wie man sieht, größer bei der Alkalispaltung als bei der Säurespaltung und in beiden Fällen größer als bei der Pepsinverdauung; die Vergleichungen müssen Spaltungsprodukte ein und desselben Proteins und annäherungsweise des gleichen Spaltungsgrads betreffen. Wir entnehmen vergleichshalber der Tabelle folgende Zahlen.

\begin{tabular}{c|c|c}
\hline \hline & $\begin{array}{c}\text { Formoltitrier- } \\
\text { barer N } \\
\text { in \% } \\
\text { des Total-N }\end{array}$ & $\begin{array}{c}\text { Ammoniak-N } \\
\text { in \% } \% \\
\text { des Total-N }\end{array}$ \\
\hline Pepsinverdautes Hühnereiweiß . . . . . & 20,4 & 3,6 \\
Hühnereiweiß; 1/2-n-HCl, 25 Tage bei 37 . & 21,1 & 5,5 \\
> 1/10-n-NaOH, 25 Tage bei 37 & 21,2 & 7,0
\end{tabular}


V. Henriques und J. K. Gjaldbæk,

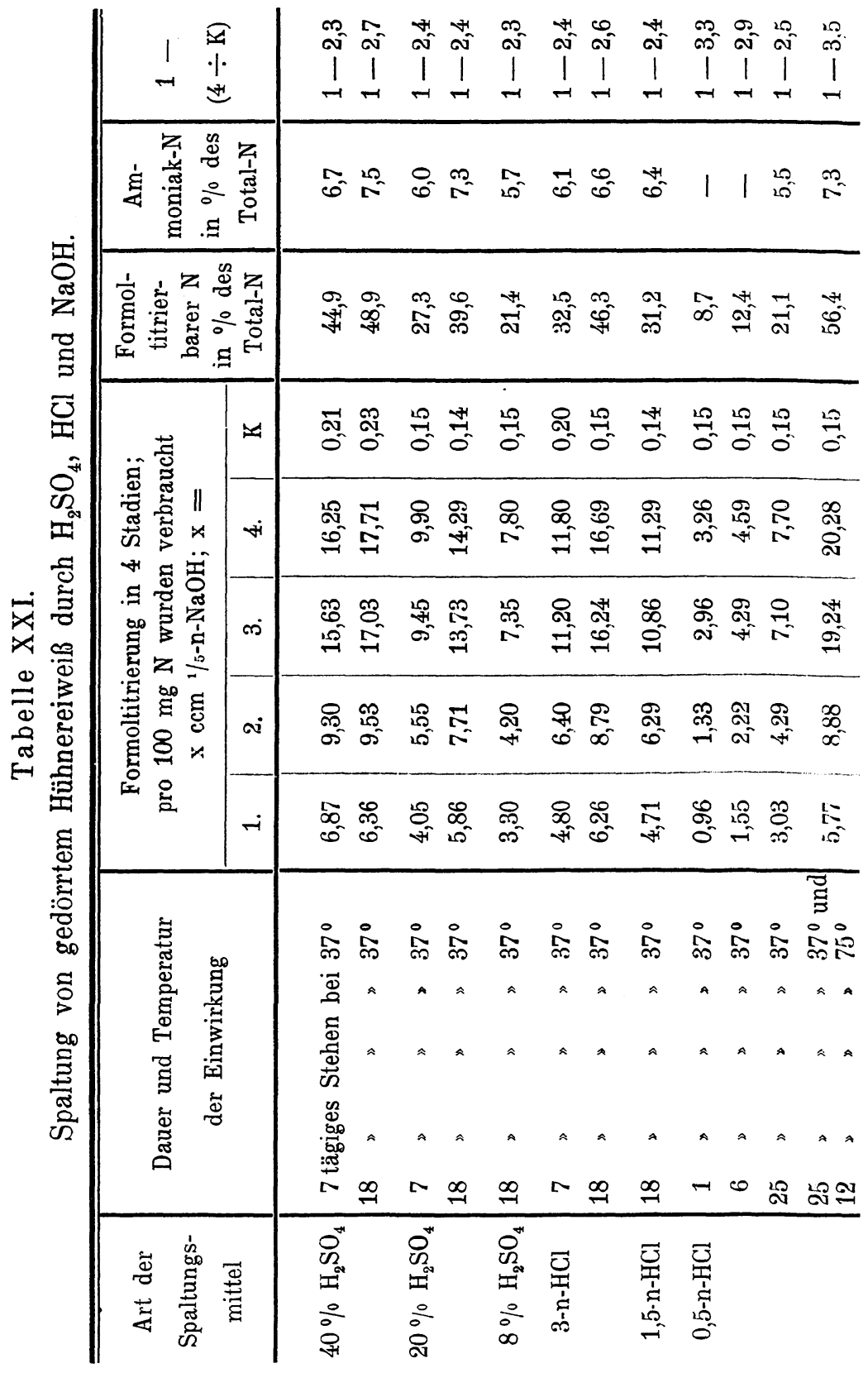


Über hydrolytische Spaltungen von Proteinen.

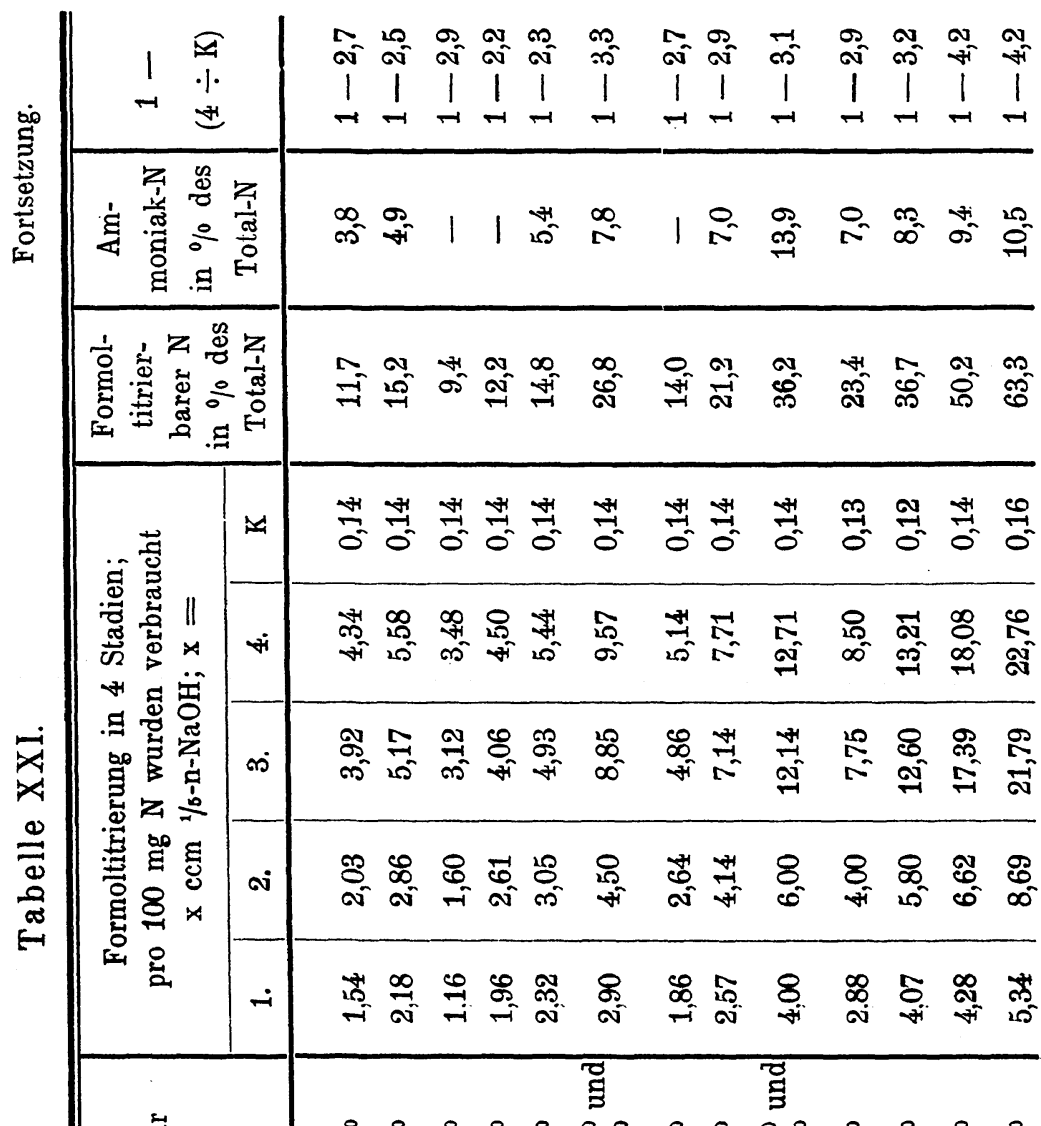

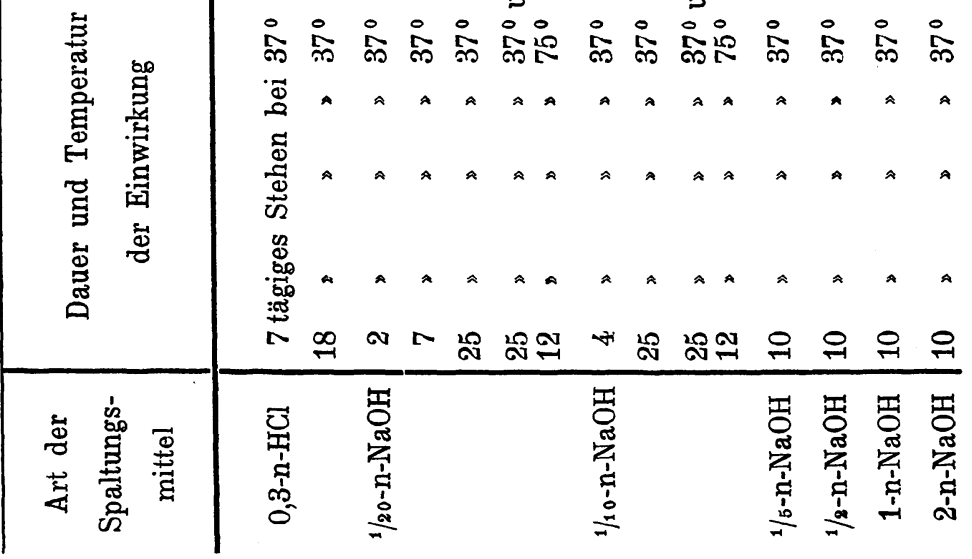


Die größere Ammoniakmenge in Säure- und Alkalispaltungsprodukten als in peptischen Spaltungsprodukten beruht vermutlich auf einer größeren sekundären Spaltung. Was die Ammoniakspaltung im übrigen betrifft, so spielt, wie man sieht, die Temperatur eine gewisse Rolle, sodaß ein bei höherer Temperatur und schwächerer Alkalikonzentration hergestelltes Spaltungsprodukt mehr Ammoniak enthält als ein entsprechendes Spaltungsprodukt (d. h. des gleichen Spaltungsgrades), das bei niedrigerer Temperatur und stärkerer Alkalikonzentration hergestellt ist. Dieser Unterschied der Ammoniakmenge erhellt deutlich aus Tabelle XXII, wenn man Versuch 1 und Versuch 4 vergleicht. Versuch 1, wo die Spaltung bei $37^{\circ}$ mit 1-n-NaOH geschah, ergibt bei einem Spaltungsgrad von $22,2 \%$ formoltitrierbaren Stickstoffs 7,4\% Ammoniak; Versuch 4 dagegen, wo die Spaltung mit $1 / 25-\mathrm{n}-\mathrm{NaOH}$ bei $150^{\circ}$ geschah, ergibt bei einem Spaltungsgrad von 20,2\% formoltitrierbaren Stickstoffs, also einem etwas niedrigeren Spaltungsgrad als in Versuch 1, eine Ammoniakmenge von 12,0\% gegen 7,4\% in Versuch 1.

Formoltitrierung in Stadien: Zur Vergleichung des Verhältnisses $1-(4 \div \mathrm{K})$ bei peptischen, tryptischen, Säureund Alkalispaltungsprodukten entnehmen wir den Tabellen untenstehende Zahlen:

\begin{tabular}{|c|c|c|c|}
\hline & $\begin{array}{l}\text { Behandlungs- } \\
\text { weise }\end{array}$ & $\left|\begin{array}{c}\text { Spaltungs- } \\
\text { grad }\end{array}\right|$ & $1-(4 \div \mathrm{K})$ \\
\hline $\begin{array}{c}\text { Peptisches Spaltungsprodukt von } \\
\text { Hühnereiweiß (Tab. II) }\end{array}$ & 65 Tage bei $37^{\circ}$ & 27,3 & $1-2,3$ \\
\hline $\begin{array}{c}\text { Tryptisches Spaltungsprodukt von } \\
\text { Hühnereiweiß (Tab. X) }\end{array}$ & 11 Tage bei $37^{\circ}$ & 24,9 & $1-5,7$ \\
\hline $\begin{array}{c}\text { Säurespaltungsprodukt von Hühner- } \\
\text { eiweiß (Tab. XXI) }\end{array}$ & $\left|\begin{array}{cc}20 \% & \mathrm{H}_{2} \mathrm{SO}_{4} \\
1 \text { Woche bei } 37^{\circ}\end{array}\right|$ & 27,3 & $1-2,4$ \\
\hline $\begin{array}{c}\text { Alkalispaltungsprodukt von Hühner- } \\
\text { eiweiß (Tab. XXI) }\end{array}$ & $\begin{array}{c}1 / 2-\mathrm{n}-\mathrm{NaOH} \\
25 \mathrm{Tage} \mathrm{bei} 37^{\circ} \\
+12\end{array}$ & 26,8 & $1-3,3$ \\
\hline
\end{tabular}

Aus diesen Zahlen wird hervorgehen, daß das Verhältnis $1-(4 \div \mathrm{K})$ das gleiche ist bei der Pepsinverdauung und der Säurespaltung, weshalb wir annehmen müssen, daß diese beiden 
Spaltungen in einer und derselben Weise verlaufen; man kann somit die Pepsinverdauung als eine Säurespaltung erklären, indem das Pepsin dann ein Katalysator der schwachen Säure wäre.

Bei der Alkalispaltung ist, wie man sieht, das Verhältnis $1-(4 \div \mathrm{K})$ weiter als bei der Pepsinverdauung und der Säurespaltung; jedoch erreicht sie bei weitem nicht die Höhe der bei der Trypsinverdauung gefundenen Werte. Indessen liegt hier ein Verhältnis vor, das nicht ohne Bedeutung ist, nämlich die Bildung von Schwefelwasserstoff, die bei Einwirkung von Alkalien auf Proteinstoffe stattfindet. Der Schwefelwasserstoff weist nämlich einen verhältnismäßig langen Abstand auf zwischen dem Lackmusneutralpunkt und dem Phenolphthaleinneutralpunkt, wie aus dem Folgenden hervorgehen wird.

$25 \mathrm{ccm}$ einer ca. 1\% 1\% Lösung von Schwefelnatrium (NB. das Salz war etwas feucht) erforderten zur Neutralisation gegenüber Phenolphthalein $5,0 \mathrm{ccm} 1 / 5 \mathrm{n}-\mathrm{HCl}$,

$$
\text { "Lackmuspapier } 8,8 \text {, } 1 / 5 \text {, }
$$

Es wird danach klar sein, daß man, wenn man eine Formoltitrierung in Stadien in einer Flüssigkeit unternimmt, die Schwefelwasserstoff enthält, von einer lackmusneutralen Losung ausgehend, einen zu hohen Formoltiter finden wird; ferner wird es klar sein, daß diese Erhöhung sowohl im 1. als im 4. Stadium der Titrierung $\mathrm{zu}$ sehen sein wird; dies bedeutet, daß man das Verhältnis $1-(4 \div \mathrm{K}) \mathrm{zu}$ eng finden wird.

Dieses Verhältnisses wegen entfernten wir aus einigen Alkalispaltungsprodukten den Schwefelwasserstoff durch Abdestillation im Vakuum mit schwacher Schwefelsäure, bevor die Formoltitrierung stattfand. Wir geben in der Tabelle XXII das Resultat dieser Versuche wieder.

Wie man sieht, stellt sich das VerhäItnis $1-(4 \div \mathrm{K})$ als etwas weiter heraus, wenn der Schwefelwasserstoff entfernt wird, allerdings nicht so weit wie bei der Trypsinverdauung. Vergleichshalber führen wir folgende Zahlen an:

Trypsinverdautes Hühnereiweiß,

$30,1 \%$ formoltitrierbarer $\mathrm{N}: 1-(4 \div \mathrm{K})=1-6,1$, Hühnereiweiß, n/10-NaOH, 11/2 Stunden

bei $150^{\circ} ; 32,7 \%$ formoltitrierbarer $\mathrm{N}: 1-(4 \div \mathrm{K})=1-5,3$. 


\section{Tabelle XXII.}

Spaltung von gedörrtem Hühnereiweiß durch $\mathrm{NaOH}$.

Vor der Formoltitrierung wurde $\mathrm{H}_{2} \mathrm{~S}$ entfernt.

\begin{tabular}{|c|c|c|c|c|c|c|c|c|c|}
\hline \multirow{2}{*}{$\begin{array}{c}\text { Kon- } \\
\text { zen- } \\
\text { tration } \\
\text { von } \\
\mathrm{NaOH}\end{array}$} & \multirow[t]{2}{*}{$\begin{array}{c}\text { Dauer und Temperatur } \\
\text { der Einwirkung }\end{array}$} & \multicolumn{5}{|c|}{$\begin{array}{l}\text { Formoltitrierung in } \\
\text { 4 Stadien; pro } 100 \mathrm{mg} \mathrm{N} \\
\text { wurden verbraucht } \\
\times \text { ccm } \mathrm{NaOH} ; \mathrm{x}= \\
\end{array}$} & \multirow[t]{2}{*}{$\begin{array}{c}\text { Formol- } \\
\text { titrier- } \\
\text { barer N } \\
\text { in } \% \text { des } \\
\text { Total }-\mathrm{N}\end{array}$} & \multirow{2}{*}{$\begin{array}{c}\text { Am- } \\
\text { moniak- } \\
\mathrm{N} \\
\text { in } \% \text { des } \\
\text { Total-N }\end{array}$} & \multirow[t]{2}{*}{$\begin{array}{c}1- \\
(4 \div \mathrm{K})\end{array}$} \\
\hline & & 1. & 2. & 3 & 4. & $\mathrm{~K}$ & & & \\
\hline $1-n$. & anden bei $37^{\circ}$ & 2,91 & 3,55 & 7,75 & 8,24 & 0,32 & & $x$ & $1-2,7$ \\
\hline $1-\mathbf{n}$. & $\bowtie 37^{\circ}$ & $3,1 \check{2}$ & 4,15 & 9,87 & 10,06 & 0,29 & 27,4 & 8,0 & $1-3,1$ \\
\hline $2-n$ & 13 tägiges Stehen bei $37^{\circ}$ & 4,8 & 7,44 & 24,72 & 25,44 & 0,24 & 70,6 & 12,0 & $1-5,3$ \\
\hline $1 / 25-n$ & $1^{1} / 2$ Stunden bei $150^{\circ}$ & 1,76 & 2,22 & 7,03 & 7,40 & 0,19 & 20,2 & 12,0 & $1-4,1$ \\
\hline $1 / 10-n$. & $>150^{\circ}$ & 2,21 & 2,83 & 11,51 & 11,86 & 0,18 & 3 & 17,3 & $1-5,3$ \\
\hline $1 / 5-n$. & $\gg 150^{\circ}$ & 3,42 & 5,12 & $\mid 16,84$ & 17,32 & $|0,24|$ & 47,8 & 21,0 & $1-5,0$ \\
\hline
\end{tabular}

Da die Ammoniakmenge indessen bedeutend größer ist in den Alkalispaltungsprodukten als in den tryptischen Verdauungsprodukten, unternahmen wir noch einige Abspaltungen, bei denen wir vor der Formoltitrierung sowohl Schwefelwasserstoff als Ammoniak entfernten; diese Versuche sind in der Tabelle XXIII angeführt.

\section{Tabelle XXIII.}

Spaltung von gedörrtem Hühnereiweiß durch $\mathrm{NaOH}$.

$\mathrm{H}_{2} \mathrm{~S}$ und $\mathrm{NH}_{3}$ wurden vor der Formoltitrierung entfernt.

\begin{tabular}{|c|c|c|c|c|c|c|c|c|c|}
\hline \multirow{2}{*}{$\begin{array}{c}\mathrm{NaOH}- \\
\text { Kon- } \\
\text { zen- } \\
\text { tration }\end{array}$} & \multirow{2}{*}{\multicolumn{2}{|c|}{$\begin{array}{c}\text { Dauer und Temperatur } \\
\text { der Einwirkung }\end{array}$}} & \multicolumn{5}{|c|}{$\begin{array}{l}\text { Formoltitrierung in } \\
4 \text { Stadien; pro } 100 \mathrm{mg} \\
\text { wurden verbraucht } \\
\mathrm{x} \mathrm{ccm} \mathrm{NaOH} ; \mathrm{x}= \\
\end{array}$} & \multirow[t]{2}{*}{$\begin{array}{c}\text { Formol- } \\
\text { titrier- } \\
\text { barer } \mathrm{N} \\
\text { in } \% \text { des } \\
\text { Total-N }\end{array}$} & \multirow[t]{2}{*}{$\begin{array}{c}1- \\
(4 \div \mathrm{K})\end{array}$} \\
\hline & & & 1. & 2. & 3. & 4. & $\mathrm{~K}$ & & \\
\hline $1-n$. & 7 tägiges Steh & bei $37^{\circ}$ & 3,11 & 5,11 & 12,88 & $|13,54|$ &, 22 & 37,3 & $1-4$ \\
\hline $1-n$. & 13 & $\triangleright 37^{\circ}$ & 2,90 & 5,51 & 14,50 & 15,66 & 0,29 & 43,0 & $1-5,3$ \\
\hline $1 / 2-\mathrm{n}$ & 11/2 Stunden & $>150^{\circ}$ & 3,85 & 7,35 & 19,95 & 22,05 & 0,35 & 60,8 & $1-5,6$ \\
\hline $1-n$. & $1 \frac{1}{2}$ & $>150^{\circ}$ & 4,44 & 8,51 & 25,16 & 28,11 & 0,37 & 77 & $1-6,3$ \\
\hline $2-n$. & $11 / 2$ & $\rtimes 150^{\circ}$ & 3,52 & $\mid 7,74$ & 25,34 & 28,8 & 0,35 & 79,8 & $1-8,2$ \\
\hline
\end{tabular}

Wir entnehmen der Tabelle die 2 ersten Versuche zur Vergleichung mit trypsinverdautem Hühnereiweiß : 


\begin{tabular}{c|c|c|c|c}
\hline \hline & $\begin{array}{c}\text { Spaltungs- } \\
\text { grad }\end{array}$ & $1-(4 \div \mathrm{K})$ & $\begin{array}{c}\text { Spaltungs- } \\
\text { grad }\end{array}$ & $1-(4 \div \mathrm{K})$ \\
\hline $\begin{array}{c}\text { Trypsinverdautes Hühner- } \\
\text { eiweiß (Tab. X) }\end{array}$ & 35,0 & $1-7,1$ & 44,1 & $1-7,9$ \\
$\begin{array}{c}\text { Alkaligespaltetes Hühner- } \\
\text { eiweiß (Tab. XXIII) }\end{array}$ & 37,3 & $1-4,3$ & 43,0 & $1-5,3$
\end{tabular}

Aus den Versuchen der Tabelle XXIII ersieht man, daß das Verhältnis $1-(4 \div \mathrm{K})$ sich als weiter herausstellt, wenn das Ammoniak und der Schwefelwasserstoff entfernt werden, als wenn diese beiden Stoffe vorhanden sind (siehe Tabelle XXI); am weitesten ist das Verhältnis $1-(4 \div \mathrm{K})$, wenn man nur den Schwefelwasserstoff aus dem Spaltungsprodukt entfernt (siehe Tabelle XXII).

Aus den angestellten Vergleichen geht hervor, daß sich das Verhältnis $1-(4 \div \mathrm{K})$ bei der Alkalispaltung als etwas enger herausstellt, als bei der Trypsinverdauung. Man kann somit diese beiden Spaltungen nicht wie die Säurespaltung und die Pepsinverdauung zusammenstellen. Möglich ist es jedoch, daß der Unterschied des Verhältnisses $1-(4 \div \mathrm{K})$ bei tryptischen Spaltungsprodukten und Alkalispaltungsprodukten von keiner prinzipiellen Art ist, und daß der Unterschied vielmehr von sekundären Spaltungen des Alkalis herrühren mag. 